\title{
Prothrombin Complex Concentrates for Bleeding in the Perioperative Setting
}

\author{
Kamrouz Ghadimi, MD, Jerrold H. Levy, MD, FAHA, FCCM, and Ian J. Welsby, BSc, MBBS, FRCA
}

\begin{abstract}
Prothrombin complex concentrates (PCCs) contain vitamin K-dependent clotting factors (II, VII, IX, and X) and are marketed as 3 or 4 factor-PCC formulations depending on the concentrations of factor VII. PCCs rapidly restore deficient coagulation factor concentrations to achieve hemostasis, but like with all procoagulants, the effect is balanced against thromboembolic risk. The latter is dependent on both the dose of PCCs and the individual patient prothrombotic predisposition. PCCs are approved by the US Food and Drug Administration for the reversal of vitamin $\mathrm{K}$ antagonists in the setting of coagulopathy or bleeding and, therefore, can be administered when urgent surgery is required in patients taking warfarin. However, there is growing experience with the off-label use of PCCs to treat patients with surgical coagulopathic bleeding. Despite their increasing use, there are limited prospective data related to the safety, efficacy, and dosing of PCCs for this indication. PCC administration in the perioperative setting may be tailored to the individual patient based on the laboratory and clinical variables, including pointof-care coagulation testing, to balance hemostatic benefits while minimizing the prothrombotic risk. Importantly, in patients with perioperative bleeding, other considerations should include treating additional sources of coagulopathy such as hypofibrinogenemia, thrombocytopenia, and platelet disorders or surgical sources of bleeding. Thromboembolic risk from excessive PCC dosing may be present well into the postoperative period after hemostasis is achieved owing to the relatively long half-life of prothrombin (factor II, 60-72 hours). The integration of PCCs into comprehensive perioperative coagulation treatment algorithms for refractory bleeding is increasingly reported, but further studies are needed to better evaluate the safe and effective administration of these factor concentrates. (Anesth Analg 2016;XXX:00-00)
\end{abstract}

$\mathrm{P}$ rothrombin complex concentrates (PCCs) are isolated from fresh-frozen plasma (FFP), which is fractionated into cryoprecipitate and cryoprecipitate-free plasma fractions through a process of slow thawing. PCCs (vitamin K-dependent factors II, VII, IX, and X) are then eluted from cryoprecipitate-free plasma, and single-factor concentrates are further derived by additional purification steps. Currently, the process of PCC production includes strict viral inactivation using solvents, detergents, pasteurization, nanofiltration, and vapor-heated treatment. ${ }^{1}$ Clinically available PCCs contain varying concentrations of constituent coagulation factors depending on the exact manufacturing process. PCCs are routinely defined as 3-factor (that contain II, IX, and X) or 4-factor (that contain II, VII, IX, and $\mathrm{X})$ formulations as shown in Table 1.

The development of PCCs emerged from the search for a purified factor IX concentrate to treat hemophilia B. ${ }^{2}$ For this reason, each factor within individual formulations is communicated as international units (IUs) per $100 \mathrm{IU}$ of factor IX (Table 1). The total dose administered is also conveyed using this standard language of IU of factor IX

From the Divisions of Cardiothoracic Anesthesiology and Critical Care Medicine, Duke University Medical Center, Durham, North Carolina.

Accepted for publication December 30, 2015.

Funding: NIH R01HL121232-01 (to IJW), and departmental funding (to KG and JHL).

Conflict of Interest: See Disclosures at the end of the article.

Reprints will not be available from the authors.

Address correspondence to Ian J. Welsby, BSc, MBBS, FRCA, Department of Anesthesiology, Duke University Medical Center, 2301 Erwin Rd., HAFS 5691H, Durham, NC 27710. Address e-mail to ian.welsby@duke.edu.

Copyright (C) 2016 International Anesthesia Research Society

DOI: 10.1213 /ANE.0000000000001188 (i.e., 500 IU of PCCs means 500 IU of factor IX), but the clinician must be aware of the PCC formulation used to know the total dose of the other coagulation factors.

Hemophiliacs can develop alloantibodies or inhibitors to purified or recombinant factor VIII (hemophilia A) or factor IX (hemophilia B) and therefore do not have the capacity to generate factor Xa through the intrinsic tenase (Xase) complex (Fig. 1). As the only treatment option for hemophiliacs with inhibiting alloantibodies to factor VIII and/or factor IX, "bypassing agents" were introduced to enhance factor Xa production through the extrinsic Xase complex of tissue factor (TF) and factor VIIa, thereby restoring thrombin generation and hemostasis. Factor VIII inhibitor bypassing activity (FEIBA $®$; Baxter Healthcare, Bloomington, IN) is the only available activated PCC (aPCC) in the United States, containing varying levels of factors VII (including appreciable amounts of factor VIIa), II, IX, and X (including very small amounts of factor Xa; Table 1). FEIBA is approved by US Food and Drug Administration (FDA) for the treatment of bleeding episodes in hemophiliacs with alloantibody inhibitors to individual factor concentrates. ${ }^{3}$ The successful use of FEIBA stimulated the development of purified bypassing agents, including activated recombinant factor VII (rFVIIa; NovoSeven $\AA$, Novo Nordisk, Denmark). The increased use of rFVIIa for this approved indication then spurred its off-label administration for the management of warfarin-related coagulopathy and refractory hemorrhage. ${ }^{4,5}$ Revisiting the mechanisms of action of these agents will provide an understanding of their clinical applications and limitations.

In this review, we examined the mechanism of action of PCCs and the importance of their individual factor components in promoting hemostasis and thrombosis. We 


\begin{tabular}{|c|c|c|c|c|c|c|c|}
\hline Brand name & Manufacturer & Factor II & Factor $\mathrm{VII}^{\mathrm{a}}$ & Factor IX & Factor $X^{a}$ & IV composition ${ }^{b}$ & Added anticoagulants $^{c}$ \\
\hline \multicolumn{8}{|l|}{ 3-factor PCCs } \\
\hline Profilnine SD & $\begin{array}{l}\text { Grifols Biologicals, Los } \\
\text { Angeles, CA }\end{array}$ & 148 & Negligible & 100 & 65 & $1000 \mathrm{IU} / 10 \mathrm{~mL}$ & None \\
\hline Bebulin & $\begin{array}{l}\text { Baxter Healthcare, } \\
\text { Bloomington, IN }\end{array}$ & 120 & Negligible & 100 & 100 & 500-700 IU/20 mL & 15 U heparin ${ }^{a}$ \\
\hline \multicolumn{8}{|l|}{ 4-factor PCCs } \\
\hline $\begin{array}{l}\text { Beriplex P/N (also } \\
\text { manufactured as } \\
\text { KCentra or } \\
\text { Confidex) }\end{array}$ & $\begin{array}{l}\text { CSL Behring, Europe/ } \\
\text { United States }\end{array}$ & 130 & 70 & 100 & $50-150$ & $500 \mathrm{IU} / 20 \mathrm{~mL}$ & $\begin{array}{l}\text { Minimal amount of } \\
\text { protein } \mathrm{C} \text { and } \mathrm{S}, \mathrm{AT} \text {, } \\
\text { and heparin }\end{array}$ \\
\hline Cofact/PPSB SD & Sanquin, The Netherlands & $60-140$ & $30-80$ & 100 & 160 & $250 \mathrm{IU} / 10 \mathrm{~mL}$ & Minimal amount of AT \\
\hline Prothromblex Total & Baxter Bioscience, Austria & 100 & 85 & 100 & 100 & $600 \mathrm{IU} / 20 \mathrm{~mL}$ & Heparin $<15 \mathrm{IU} / \mathrm{mL}$ \\
\hline Octaplex & Octapharma, Austria & $56-152$ & $36-96$ & 100 & $72-120$ & $500 \mathrm{IU} / 20 \mathrm{~mL}$ & $\begin{array}{l}\text { Protein C: } 52-124 \mathrm{IU}^{\mathrm{a}} \\
\text { Protein S: } 48-128 \mathrm{IU}^{\mathrm{a}} \\
\text { Heparin: } 16-62 \mathrm{U}^{\mathrm{a}}\end{array}$ \\
\hline \multicolumn{8}{|l|}{ aPCCs } \\
\hline FEIBA NF & $\begin{array}{l}\text { Baxter Healthcare, } \\
\text { Bloomington, IN }\end{array}$ & $\begin{array}{l}86.7 \\
\text { Ila: } 0.07^{a}\end{array}$ & $\begin{array}{l}66.7 \\
\text { VIIa: } 100^{a}\end{array}$ & $\begin{array}{c}100 \\
\text { IXa: } 0.03^{a}\end{array}$ & $\begin{array}{c}66.7 \\
\text { Xa: } 0.4^{a}\end{array}$ & $500 \mathrm{IU} / 20 \mathrm{~mL}$ & Protein C: $66.7^{a}$ \\
\hline
\end{tabular}

aPCC = activated prothrombin complex concentrates; $A T=$ antithrombin; FEIBA $=$ factor eight inhibiting activity; IU = international units; NF = nanofiltration (refers to process of viral inactivation); $\mathrm{PCCs}=$ prothrombin complex concentrates; $\mathrm{P} / \mathrm{N}=$ pasteurization and nanofiltration (refers to process of viral inactivation); $\mathrm{SD}=$ solvents and detergents (refers to process of viral inactivation).

aIU per $100 \mathrm{IU}$ of factor IX.

bIU of factor IX included per volume of sterilized water.

${ }^{c}$ Most PCC formulations contain anticoagulants to prevent activation of coagulation factors when the solute is diluted in sterile water.

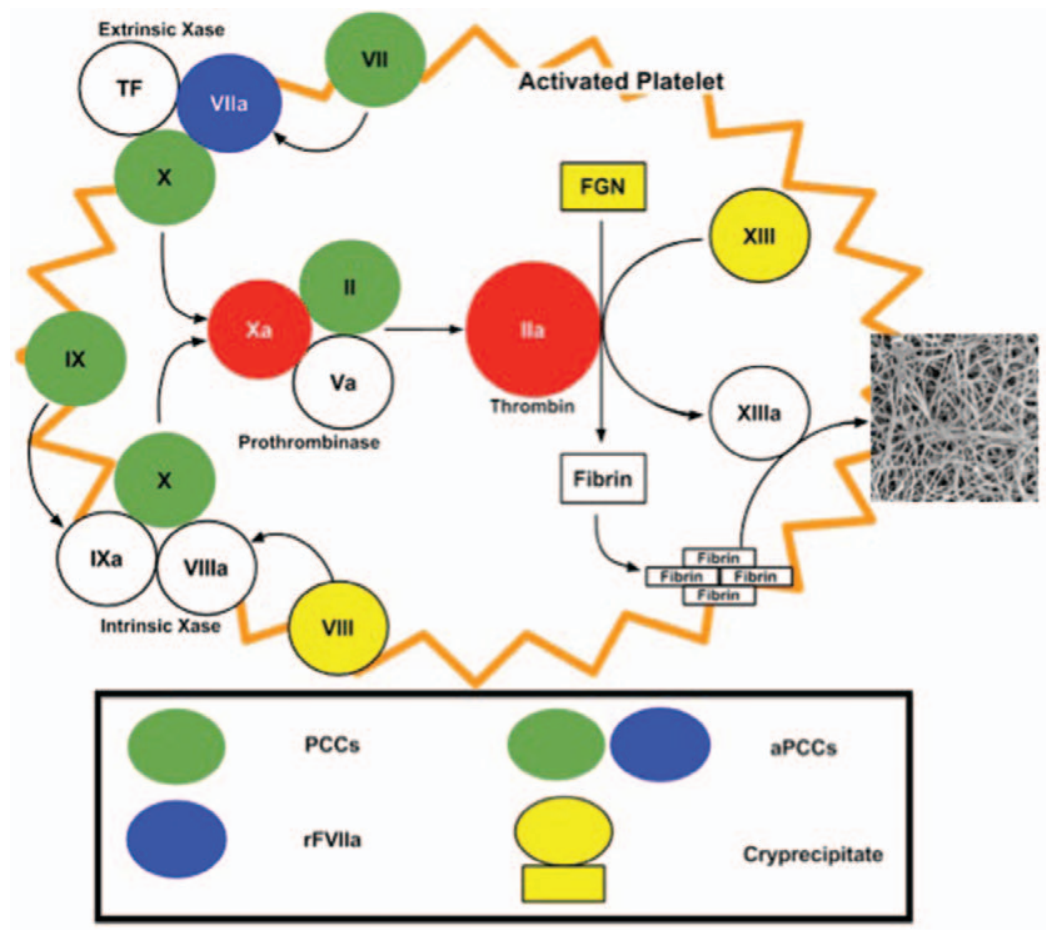

Figure 1. A depiction of the coagulation cascade with focus on factor-enzyme complexes (tenase, prothrombinase) and target locations for direct factor repletion by prothrombin complex concentrates, activated prothrombin complex concentrates, activated recombinant factor VII, and cryoprecipitate. Extrinsic tenase contains TF, factor X, and factor VIla, whereas intrinsic tenase contains factor X, factor IXa, and factor VIIla. Both types of tenase influence the production of factor Xa, which then joins with factor Va to form prothrombinase. Prothrombinase converts the substrate prothrombin (factor II) into thrombin (factor Ila). Thrombin facilitates (1) the conversion of FGN into fibrin monomers and (2) converts fibrin-stabilizing factor (XIII) into its activated form (XIIla) to facilitate fibrin polymerization and cross-linkage (scanning electron micrographic image insert of normal, dense fibrin deposition). These 2 reactions occur independent of one another in the presence of thrombin. The color-coded legend below the coagulation model delineates which factor concentrate repletes individual factor constituents. FGN concentrate repletes FGN alone, but for purposes of clarity, it is not illustrated. In addition, aPCCs contain clinically negligible concentrations of factors Ila, IXa, and Xa (not illustrated). aPCCs = activated prothrombin complex concentrates; FGN = fibrinogen; PCCs = prothrombin complex concentrates; rFVIIa = activated recombinant factor VII; TF = tissue factor; Xase = tenase. 
further discuss the formulations of PCCs commercially available and their approved and off-label indications. Of note, localized thrombus formation is important for clinical hemostasis, and clinicians are reminded that PCCs are only one component of multimodal therapy for coagulopathic bleeding.

\section{MECHANISMS OF ACTION}

Knowledge of the mechanism of the procoagulant effects of rFVIIa, aPCCs, and PCCs is important to understand the indications and limitations of their use in various clinical scenarios. The calcium-dependent reactions of vitamin K-dependent proteases (factors IIa, VIIa, IXa, and Xa) and their nonenzymatic cofactor proteins (TF, factor VIIIa, and factor Va) are illustrated in a simplified model of hemostasis (Fig. 1). The noted cofactors are localized to the site of coagulation by receptors on the surface of activated platelets forming anticoagulant-resistant, enzymatic complexes. Briefly, TF-dependent generation of small quantities of factor Xa by the extrinsic Xase complex (TF and factor VIIa) initiates prothrombinase (factors $\mathrm{Va}$ and $\mathrm{Xa}$ )-dependent thrombin (factor IIa) generation. Thrombin activates platelets and factors V, VIII, and XI and catalyzes intrinsic Xase assembly that efficiently accelerates the generation of factor Xa. Intrinsic Xase generates factor Xa by 100 times more than extrinsic Xase. Factor Xa supplies the prothrombinase complex, which is now 10,000 times more effective in the presence of factor Va. ${ }^{6}$ Thrombin generation rapidly converts fibrinogen to fibrin and crosslinked fibrin monomers (through factor XIIIa) into a dense, lysis-resistant thrombus (Fig. 1). The loss of intrinsic Xase activity in hemophiliacs because of the presence of inhibitor alloantibodies minimizes factor Xa production, depriving the prothrombinase complex of its thrombin generation capacity. Partial restoration of factor $\mathrm{Xa}$ activity can occur with the administration of rFVIIa and possibly more so with aPCCs (containing variable amounts of both factors VIIa and Xa). Furthermore, the additional prothrombin (factor II) provided by aPCCs may better restore thrombin generation, albeit at the expense of thromboembolic risk when repeat dosing excessively increases prothrombin concentrations. ${ }^{1}$
Non-aPCCs, as previously mentioned, are categorized as 3- or 4-factor ( $3 \mathrm{~F}$ or $4 \mathrm{~F}$ ) on the basis of the presence or absence of appreciable concentrations of factor VII. Table 1 outlines the factor VII concentrations in each PCC formulation. The values for formulations containing appreciable concentrations of factor VII range from 30 to 100 IU per 100 IU of factor IX. Of note, the concentrations of procoagulants (factors II, IX, X, and VII when present) and anticoagulants (antithrombin III or heparin and proteins C, S, and Z) present are variable and depend on the formulation (Table 1). These anticoagulants are present presumably to prevent activation of coagulation factors when the solute is diluted in sterile water. 3F-PCCs have also been used to acutely reverse the anticoagulant effects of warfarin ${ }^{7}$ but may be less effective in normalizing the prothrombin time (PT) or international normalized ratio (INR) because of the lack of factor VII. Factor VII has a profound in vitro effect on the INR test. 8 ,9 This notion is supported by the observation that clinically important hemostasis may be achieved when only $30 \%$ of normal factor VII activity is present in the setting of increased INR values. ${ }^{10}$ Furthermore, the rapid correction of INR shortly after the administration of rFVIIa may mask other coagulation deficiencies that may contribute to a prolonged INR value.

Nonactivated, 4F-PCCs are FDA-approved for the urgent reversal of acquired coagulation factor deficiency induced by vitamin $\mathrm{K}$ antagonists in adult patients with acute major bleeding (Fig. 2) ${ }^{11}$ Restoring depleted levels of factors II, VII, IX, and X restores factor Xa generation in warfarin-treated patients, resulting in the replenishment of the prothrombinase complex and subsequent thrombin generation. Prothrombotic tendency and thromboembolic risk increase if excessive factor II is formed. In contrast, rFVIIa may restore factor $\mathrm{Xa}$ generation, ${ }^{12,13}$ but rFVIIa has a short half-life, it does not restore factor IX or factor $X$ concentrations (and thus Xase activity) to baseline, and it does not directly replenish factor II or restore thrombin generation. ${ }^{12}$ Because factor II levels are proportional to thrombin (factor IIa) generation, factor II is essential in preserving and promoting hemostatic efficacy. ${ }^{13}$ Inappropriate repeat dosing of rFVIIa may be used in an attempt to achieve hemostasis

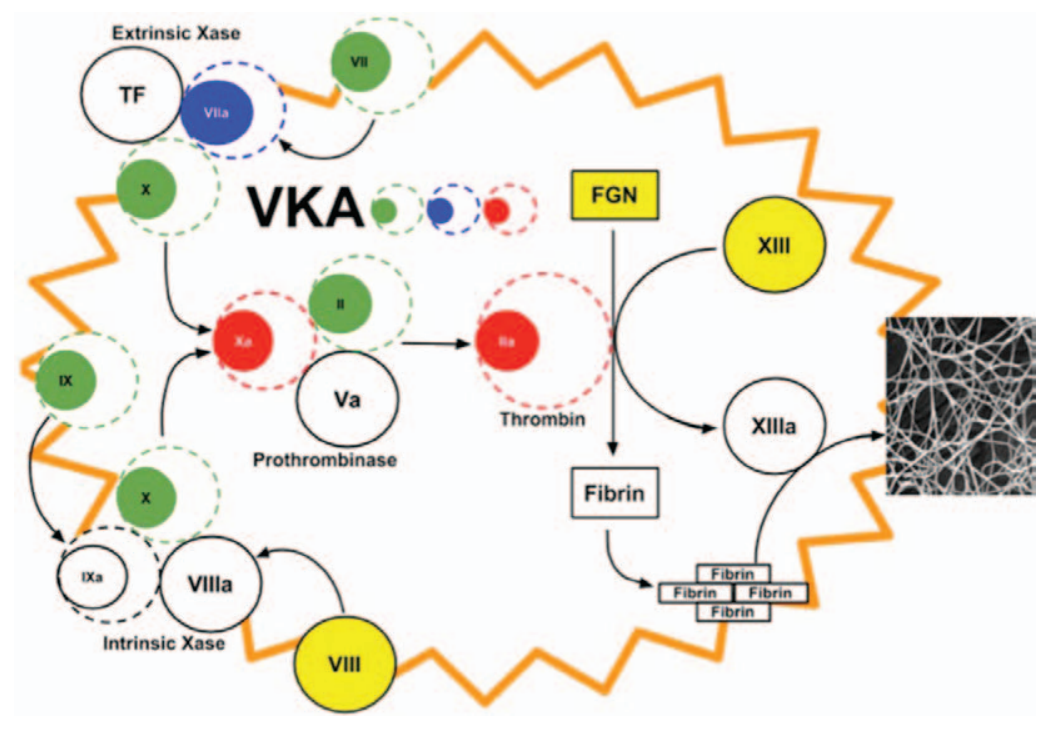

Figure 2. Reduced concentrations of coagulation factors II, VII, IX, and X as a result of administration of VKA and its impact on thrombin generation and fibrin polymerization (scanning electron micrographic image insert of weak fibrin crosslinkage). VKAs also act to reduce the synthesis of coagulants downstream from the vitamin K-dependent coagulation factors, therefore weakening the resultant fibrin crosslinkage. Vitamin K-dependent anticoagulants (protein $\mathrm{C}$ and $\mathrm{S}$ ) are not illustrated. FGN = fibrinogen; TF = tissue factor; VKA = vitamin$\mathrm{k}$ antagonist(s); Xase $=$ tenase. 
in the perioperative setting. However, once factor II concentrations are subsequently restored (i.e., with plasma or PCCs), excessive, residual rFVIIa-related factor Xa production may lead to pathologic thrombus formation. Although factor II levels are considered most important, even mild factor X deficiency (25\%-50\% activity) can be associated with periprocedural bleeding complications in patients with acquired deficiencies. ${ }^{14}$ Therefore, initially replacing all depleted factors with PCCs is preferred to repeated dosing of rFVIIa from a mechanistic point of view.

Coagulopathy resulting from cardiopulmonary bypass (CPB) and trauma occurs in part because of the hemodilution of additional components necessary for the coagulation cascade. ${ }^{15-17}$ This occurs in trauma as a result of administering nonplasma intravascular volume expanders (e.g., crystalloid solutions, packed red blood cells) in the setting of hypotension during hemorrhage. During cardiac surgery, hemodilution is encountered on initiation of CPB when patients' whole blood volume is combined with nonplasma volume expanders primed in the CPB circuit. These scenarios may lead to a decrease in both procoagulant and anticoagulant factors. In addition, existing consumptive coagulopathy may lead to decreased procoagulant constituents. Factor concentrations initially maintain clinically important hemostasis, to generate thrombin, until critically low levels of procoagulant components are reached. Fibrinogen is the first constituent to reach these critical levels during acquired surgical bleeding, ${ }^{18,19}$ and replenishing this alone has been sufficient for the correction of coagulopathy related to complex cardiac surgery. ${ }^{20}$ Cryoprecipitate will restore fibrinogen, factors VIII and XIII, and von Willebrand Factor (Fig. 1). When considering rFVIIa, aPCCs, or PCCs to restore thrombin generation, clinicians should keep in mind that only aPCCs and PCCs provide factor II (prothrombin). However, these compounds will be ineffective in correcting clinically important coagulopathy without adequate repletion of critical hemostatic components such as fibrinogen and platelets. ${ }^{21,22}$

Although the potential for unopposed thrombin generation remains a concern with the administration of $4 \mathrm{~F}-$ or 3F-PCCs, FFP contains both coagulation factors and naturally occurring anticoagulants. Furthermore, FFP administration should always be considered with ongoing intravascular volume resuscitation in the setting of active bleeding. With that said, large volumes of plasma only slowly normalize depleted factor levels when compared with the rapid correction that occurs with PCCs. ${ }^{11}$ Therefore, it is reasonable to consider the administration of FFP with PCCs to mitigate the prothrombotic risk.

As discussed earlier, rFVIIa triggers extrinsic Xase complex-related generation of factor Xa without directly providing factor II substrate for thrombin generation, which is otherwise directly provided with PCCs. Therefore, initial administration of rFVIIa may appear clinically inadequate for hemostasis and lead to repeated administration and eventual overcorrection of thrombin generation by indirectly increasing the prothrombinase levels (Fig. 1). Notably, the longer half-lives of factor II (60-72 hours) and factor X (40-45 hours) provided by PCCs either confer a longer duration of hemostasis than rFVIIa or a predisposition to thrombosis depending on the clinical circumstances.

\section{SIGNIFICANCE OF THROMBIN GENERATION}

The capacity to restore thrombin generation is critical to the mechanism of action of PCCs (Fig. 1). The ability of PCCs to support the enzyme complexes that convert factor II to IIa illustrates their efficacy as hemostatic agents and potentially contributing to the prothrombotic risk. In vitro assays such as the calibrated automated thrombogram (CAT®; Thrombinoscope, Inc., Parsippany, NJ) provide a sensitive blood assay for thrombin generation. ${ }^{23-25}$ CAT is not yet FDAapproved for clinical use and, thus, is limited to research. This assay promises clinically relevant insight into the management of hemostasis and thrombosis by risk-stratifying patients according to the ability of thrombin generation during various clinical scenarios. These include hemophiliacs, ${ }^{26}$ other congenital factor deficiencies, ${ }^{27}$ patients undergoing cardiac surgery experiencing perioperative hemorrhage, ${ }^{28-30}$ and the general population of patients for venous thromboembolic disease. ${ }^{31-33}$ Determining thrombin generation capacity after the administration of hemostatic agents may be a worthwhile model of determining clinical response to treatment during vitamin $\mathrm{K}$ antagonist reversal. ${ }^{34-36}$ Of note, in vivo thrombin generation may be inferred by increased serum levels of prothrombin F1.2 levels and thrombin-antithrombin complexes. ${ }^{37}$ Prothrombin F1.2 is a peptide with a 90-minute half-life, which is cleaved into circulation when prothrombin is transformed into thrombin. ${ }^{37}$ The assay for quantification of this fragment is currently unavailable in the clinical setting for acute decision-making.

Thrombin generation is impaired during CPB in a manner similar to that of consumptive coagulopathy. Interestingly, however, there is a $>50 \%$ reduction in antithrombin III levels secondary to hemodilution. ${ }^{38}$ Coagulation factor consumption after CPB may be associated with the coagulopathy set in motion during $\mathrm{CPB}$ and inadequate clot stabilization. ${ }^{37}$ Reduced preoperative thrombin-generating capacity has strongly correlated with increased postoperative bleeding $(r=0.7, P<0.001)$, illustrating the predictive value of this assay. ${ }^{39}$ Low values of peak thrombin generation were predictive of blood loss after CPB in a study of 30 patients undergoing coronary artery bypass graft surgery, when thrombin generation was measured both before heparinization and after an appropriate dose of protamine had been administered. ${ }^{28}$ Similarly, during pediatric cardiac surgery, thrombin generation variables were uniformly improved after platelet and cryoprecipitate transfusions. ${ }^{29}$ After administration of cryoprecipitate and platelets, the rate and peak of thrombin generation were modeled to increase with the in vitro addition of 3F-PCCs, but not with the addition of rFVIIa. ${ }^{29}$ This difference in thrombin generation curves between administration of PCCs and rFVIIa is consistent with the mechanism of generalized factor deficiency where PCCs provide factor II but rFVIIa does not (Fig. 1). In a cell-based model of coagulation, most factors display a threshold relationship with thrombin generation such that marked coagulation factor deficiency is required before thrombin generation is adversely affected. ${ }^{13}$ In contrast, factor II levels are understandably in direct proportion to thrombin generation. ${ }^{13}$ This effect is relevant both for physiologic hemostasis and pathologic thrombosis. Even patients with congenital coagulation factor deficiency (e.g., hemophiliacs) have merely a mild bleeding phenotype 
if thrombin generation is maintained by compensatory increases in other factors. ${ }^{26,27}$ Conversely, thromboembolic disease is associated with excessive prothrombin/FII lev$\mathrm{els}^{1,40}$ and high levels of thrombin generation. ${ }^{31-33}$ Once again, the long half-lives of administered factor II and factor $\mathrm{X}$ may persist after a period of coagulopathy, which may turn result in a bleeding tendency to a prothrombotic risk. In this setting, careful consideration should be paid to postoperative venous thromboembolism prophylaxis and that adequate levels of anticoagulants such as antithrombin III are present.

The promise of the ability to clinically determine thrombin generation during the perioperative period may provide a potential guide for targeted PCC administration while avoiding thromboembolic events. Efforts to develop readily available viscoelastic tests to also provide an estimate of thrombin generation are, currently, being evaluated in pediatric cardiac surgery. ${ }^{41}$

\section{APPROVED AND OFF-LABEL USES FOR PCCS}

As discussed earlier, the FDA-approved indication for 4F-PCCs is for the urgent reversal of acquired coagulation factor deficiency induced by vitamin K antagonist therapy in adult patients with acute major bleeding or need for an urgent surgery/invasive procedure (Table 2; Fig. 2). ${ }^{36,42-52}$ KCentra ${ }^{\circledR}$ (CSL Behring, King of Prussia, PA) is the only 4 -factor formulation approved for this indication in the United States. Vitamin K antagonists such as warfarin effectively prevent essential posttranslational $\gamma$-carboxylation of the hepatically synthesized coagulation factors (II, VII, IX, and X; Fig. 2) and anticoagulants (proteins C, S, and Z). ${ }^{54}$ In the past, the administration of FFP was the only option for the urgent reversal of the effects of vitamin K antagonists, which included patients requiring urgent or emergent surgery. The use of PCCs for this purpose has several benefits over the administration of FFP. These advantages include a more rapid INR normalization, similar or improved hemostatic efficacy, less volume administered (e.g., $100 \mathrm{~mL}$ for 2500 IU KCentra vs $1000 \mathrm{~mL}$ of FFP), no need for crossmatching, and no risk for complications directly related to transfusion particularly transfusion-related acute lung injury. ${ }^{11}$ In the setting of hypovolemia and bleeding, administration of FFP may be advantageous for managing both the clinical issues. Even in such a clinical setting, PCCs will more rapidly correct coagulopathy and enable appropriate intravascular volume resuscitation using nonalloimmunogeneic solutions. ${ }^{53}$ Guidelines and consensus statements now recommend PCCs equally or in preference to FFP for urgent vitamin $\mathrm{K}$ antagonist reversal (Table 2). ${ }^{36,42-52}$

The pivotal trial in the FDA approval of 4F-PCCs was a prospectively randomized, plasma-controlled, study involving 202 patients enrolled at 36 centers demonstrating that 4F-PCCs were an effective alternative to FFP for the urgent reversal of vitamin $\mathrm{K}$ antagonist therapy. ${ }^{11}$ In that study, nonsurgical patients prescribed vitamin $\mathrm{K}$ antagonists were administered KCentra (also known as Beriplex $\mathrm{P} / \mathrm{N} \circledast$, CSL Behring; $n=98)$ or FFP $(n=102)$ after presenting with severe bleeding. The primary endpoints included 24-hour clinical hemostatic efficacy and INR correction $(\leq 1.3) 30$ minutes after the end of infusion. ${ }^{11}$ Hemostasis was achieved in 71 patients $(72.4 \%)$ receiving PCCs and 68 patients $(65.4 \%)$ receiving FFP. ${ }^{11}$ Protocolized weight-based dosing of PCCs and FFP was determined by baseline INR ${ }^{11}$ Coagulation factors and anticoagulants in 4F-PCCs achieved higher concentrations faster when compared with FFP infusion but eventually reached similar levels by 24 hours. Factors II and $X$ and protein $C$ levels were consistently higher at any given time point in the PCCs group $(P<0.0001)$. INR corrected

\begin{tabular}{|c|c|c|c|}
\hline Society clinical practice guideline & Year & Recommendation for PCCs & Dose of PCCs and other agents ${ }^{a}$ \\
\hline $\begin{array}{l}\text { American Society of } \\
\text { Anesthesiologists }^{52}\end{array}$ & 2015 & $\begin{array}{l}\text { Urgent VKA reversal or excessive bleeding } \\
\text { and increased INR }\end{array}$ & $\begin{array}{l}\text { No specific dosing regimen; consider FFP or PCCS } \\
\text { for urgent warfarin reversal }\end{array}$ \\
\hline $\begin{array}{l}\text { European Task Force for Advanced } \\
\text { Bleeding in Trauma }{ }^{47}\end{array}$ & 2013 & $\begin{array}{l}\text { Reversal of VKA and factor Xa inhibitors (but } \\
\text { not recommended for reversal of DTIs) }\end{array}$ & $\begin{array}{l}\text { Dosing based on point-of-care testing algorithm } \\
\left(\text { e.g., } \mathrm{TEG}^{\circledast}, \mathrm{ROTEM}^{\circledast}\right)\end{array}$ \\
\hline $\begin{array}{l}\text { American College of Chest } \\
\text { Physicians }{ }^{45}\end{array}$ & 2012 & First-line agent for urgent VKA reversal & $\begin{array}{l}\text { Vitamin K 5-10 mg IV + 4F-PCCS (no specific } \\
\text { dosing regimen) }\end{array}$ \\
\hline $\begin{array}{l}\text { STS/Society of Cardiovascular } \\
\text { Anesthesiologists Blood } \\
\text { Conservation }{ }^{44}\end{array}$ & 2011 & $\begin{array}{l}\text { First-line for urgent VKA reversal (4F-PCCS) } \\
\text { (may substitute FFP for 3F-PCCS if } \\
\text { continued bleeding) }\end{array}$ & No specific dose provided \\
\hline $\begin{array}{l}\text { Canadian National Advisory Committee } \\
\text { on Blood and Blood Products }{ }^{50}\end{array}$ & 2011 & $\begin{array}{l}\text { VKA reversal for bleeding manifestations } \\
\text { or surgical intervention required }<6 \mathrm{~h} \text { of } \\
\text { presentation }\end{array}$ & $\begin{array}{l}\text { INR unknown: } 80 \mathrm{~mL} \text { (4F-PCCS, } 2000 \mathrm{IU}) \\
\text { INR <3.0: } 40 \mathrm{~mL} \text { (4F-PCCS, } 1000 \mathrm{IU}) \\
\text { INR = 3.0-5.0: } 80 \mathrm{~mL}(4 \mathrm{~F}-\mathrm{PCCS}, 2000 \mathrm{IU}) \\
\text { INR >5.0: } 120 \mathrm{~mL} \text { (4F-PCCS, } 3000 \mathrm{IU})\end{array}$ \\
\hline AHA/American Stroke Association ${ }^{49}$ & 2010 & VKA-associated IC & 3F-PCCS or FFP (no specific dosing regimen) \\
\hline French Clinical Practice Guidelines ${ }^{36}$ & 2010 & First-line agent for urgent VKA reversal & $\begin{array}{l}\text { Vitamin K 5-10 mg orally + INR unknown: 4F-PCCs, } \\
25 \text { IU/kg; INR known: use SPC }\end{array}$ \\
\hline European Stroke Initiative $^{51}$ & 2006 & VKA-associated ICH, increased INR & $\begin{array}{l}\text { Vitamin K 5-10 mg IV + 4F-PCCs 10-50 IU/kg or } \\
10-40 \text { mL/kg FFP (initial INR-dependent dose) }\end{array}$ \\
\hline $\begin{array}{l}\text { British Committee for Standards } \\
\text { in Haematology }{ }^{42}\end{array}$ & 2005 & First-line agent for VKA reversal & $\begin{array}{l}\text { Vitamin K 5-10 mg orally + "factor concentrate" } \\
\text { (3F- or 4F-PCCs not specified, no specific dosing }\end{array}$ \\
\hline $\begin{array}{l}\text { Australasian Society of Thrombosis } \\
\text { and Haemostasis }{ }^{43}\end{array}$ & 2004 & $\begin{array}{l}\text { VKA reversal if any significant bleeding or } \\
\text { INR }>9\end{array}$ & $\begin{array}{l}\text { Vitamin K } 1 \mathrm{mg} \text { IV + 3F-PCCs } 25-50 \mathrm{IU} / \mathrm{kg}+ \\
\text { 150-300 mL FFP }\end{array}$ \\
\hline
\end{tabular}

DTIs = direct thrombin inhibitors; FFP = fresh-frozen plasma; ICH = intracranial hemorrhage; INR = international normalized ratio; PCCs = prothrombin complex concentrates; ROTEM = rotational thromboelastometry; SPC = summary of product characteristics (document required by European Commission and available online); STS = Society of Thoracic Surgeons; TEG = thromboelastography; VKA = vitamin-K antagonist; 3F-PCC = 3-factor PCCs; 4F-PCC = 4-factor PCCs. ${ }^{a}$ Vitamin $\mathrm{K}$ alone continues to be recommended by guideline committees in the setting of nonurgent VKA reversal. 
faster in the PCCs group $(P<0.0001)$, but both groups displayed statistically similar corrected INR values at 24 hours (INR $\leq 1.3, P=0.08$ ). Importantly, the safety profiles (adverse events, serious adverse events, thromboembolic episodes, and death) were similar between the groups. ${ }^{11}$

A consistent feature among studies evaluating the reversal of vitamin K antagonist-induced coagulopathy has been the reduction of an increased pretreatment INR of $>2$ to 6 to an INR of $<1.5$ at approximately 15 to 60 minutes after administration of 4F-PCCs. ${ }^{11,55-58}$ Concomitant administration of IV vitamin $\mathrm{K}$ is essential to promote the hepatic synthesis of procoagulant and anticoagulant factors for sustained normalization of coagulation and modulation of thrombosis. However, IV vitamin $\mathrm{K}$ often requires at least 12 hours before clinical efficacy is observed. ${ }^{59}$ Oral vitamin $\mathrm{K}$ is less reliably absorbed, and timing is less clear. ${ }^{59}$ Although PCCs more rapidly correct coagulopathy related to vitamin $\mathrm{K}$ antagonists compared with FFP, current guidelines continue to recommend vitamin $\mathrm{K}$ administration along with PCCs. Restoration of endogenous thrombin generation after administration of 4F-PCCs (Beriplex P/N) or rFVIIa (NovoSeven) for vitamin $\mathrm{K}$ antagonist reversal has been evaluated in animal and human subjects. ${ }^{12}$ Thrombin generation is only restored with 4 F-PCCs but not rFVIIa (150 vs $50 \mathrm{nM} ; P<0.05$ ), although both drugs correct INR values. This observation reiterates the importance of prothrombin for thrombin generation and the significance of factor VII simply for INR value normalization. ${ }^{12}$ Of note, aPCCs (FEIBA) and rFVIIa have been described for the reversal of vitamin $\mathrm{K}$ antagonists, but their use is not approved for this indication. ${ }^{60,61}$

\section{Lessons from Activated Recombinant Factor VII}

Before embarking on extensive perioperative use of PCCs, there is an opportunity to learn from our overenthusiastic initial adoption of rFVIIa, which was subsequently tempered by potential thromboembolic risk.,5,62 The half-life of factor VII is approximately 6 hours, whereas that of factor II is 60 to 72 hours. ${ }^{54}$ Moreover, the half-life of rFVIIa may be even shorter than 6 hours owing to the increased volume of distribution when compared with the longer plasmaderived factor VII. ${ }^{63}$ This is an important fact, which merits caution against zealous PCC administration because of a far greater thromboembolic risk when compared with rFVIIa. The use of rFVIIa in high-risk cardiac surgical cases with refractory hemorrhage has been described in retrospective studies. ${ }^{21,64,65}$ Identified predictors of treatment failure included baseline INR $>2.0$, platelet count $<80 \times 10^{9} / \mathrm{L}$, fibrinogen levels $<100 \mathrm{mg} / \mathrm{dL}$, and $>15$ units of packed red blood cells transfused before administration of rFVIIa. ${ }^{21}$ High thromboembolism rate $(>20 \%),{ }^{22}$ a complication rate of $44 \%,{ }^{21}$ and a mortality of $32 \%{ }^{21}$ were also described.

Effective hemostasis with low-dose rFVIIa (defined as $\leq 40 \mu \mathrm{g} / \mathrm{kg}$ ) in cardiac surgery has been reported in prospective $^{66}$ and retrospective ${ }^{64}$ studies. Reduced bleeding is observed in propensity-matched studies when patients undergoing cardiac surgery receive low-dose rFVIIa compared with placebo. ${ }^{64,67}$ Intuitively, fewer adverse thromboembolic effects would be expected with lower doses of rFVIIa, and the higher doses (70-90 $\mu \mathrm{g} / \mathrm{kg})$ used for bypassing activity in hemophiliacs are unnecessary in the nonhemophiliac surgical patient because the intrinsic Xase enzyme complex is intact. Failure to address platelet; fibrinogen; and factors II, VIII, IX, or X deficiencies in patients with severe hemorrhage will limit the effectiveness of rFVIIa to restore thrombin generation and fibrin clot formation (Fig. 1, normal coagulation model). This assertion is supported by Karkouti et al. ${ }^{21}$ who observed that hypofibrinogenemia ( $<100 \mathrm{mg} / \mathrm{dL})$ and thrombocytopenia $(<80 \times$ $10^{9} / \mathrm{L}$ ) before and after rFVIIa administration are associated with hemostasis failure, as previously discussed.

Administration of rFVIIa has profound effects on the INR, which is a test that is very sensitive to factor VII levels. ${ }^{10}$ Therefore, failure to decrease INR below a value of 1.0 with low-dose rFVIIa administration indicates profound predose factor VII deficiency. ${ }^{68}$ Similarly, a prolonged activated partial thromboplastin time (aPTT, a measure of the intrinsic and common coagulation pathways) is independently associated with failure of hemostasis after rFVIIa for refractory hemorrhage. ${ }^{69}$ Addressing concomitant deficiencies of other coagulation components before administering rFVIIa is, therefore, prudent. Conversely, the use of high-dose rFVIIa followed by correction of these deficiencies may lead to thromboembolic complications. With that said, rFVIIa as a general hemostatic agent remains unproven in addition to concerns about thromboembolism. ${ }^{4,5,62}$ A 2011 Cochrane database review of 3500 patients across 25 randomized controlled trials (nonsurgical as well as noncardiac and cardiac surgery patients) found modest blood loss after rFVIIa administration either for prophylactic or therapeutic means. ${ }^{4}$ Eleven of the 25 trials $(n=$ 2366) involving therapeutic use of rFVIIa found an increase in the thromboembolic events (relative ratio [RR], 1.21; 95\% confidence interval, $0.93-1.58)$. Thirteen trials $(n=1137)$ assessing the prophylactic use also found a trend toward thromboembolisms (RR, 1.32; 95\% confidence interval, 0.84-2.06). ${ }^{4}$ Interestingly, no differences were found in thromboembolic events when comparing all comers receiving low-dose rFVIIa (defined as $<80 \mu \mathrm{g} / \mathrm{kg}$ ) and standard/higher doses ( $\geq 80 \mu \mathrm{g}$ ) $\mathrm{kg}$ ), but the authors of the Cochrane review indicated inadequate statistical power and variable definitions of high- and low-dosage levels as contributors to these statistically nonsignificant findings regarding thromboembolism. ${ }^{4}$

Preliminary observational reports support the use of PCCs for refractory high-risk cardiovascular surgical bleeding. This approach may be more mechanistically logical compared with rFVIIa administration as previously discussed and depicted (Fig. 1). ${ }^{70,71}$ Investigators in one propensity-matched study administered 10 to $15 \mathrm{IU} / \mathrm{kg}$ of 4F-PCCs before low-dose rFVIIa (median, $18 \mu \mathrm{g} / \mathrm{kg}$; interquartile range, 9-16 $\mu \mathrm{g} / \mathrm{kg}$ ) and found reduced bleeding after cardiac surgery. ${ }^{67}$ This combination of low-dose rFVIIa and PCCs may confer advantages over the use of rFVIIa alone. There is insufficient evidence, however, to support this approach without using point-of-care and laboratoryguided testing within an algorithm for refractory bleeding to help prevent thromboembolic disease. ${ }^{53,72,73}$

\section{Cardiac Surgery and Cardiopulmonary Bypass}

Determining the serum levels of factors II, VII, IX, and X in individual patients before PCC administration in each 
clinical scenario may be helpful to guide appropriate PCC dosing assuming that laboratory values may be reported in a timeframe to be clinically useful. This strategy may be especially helpful to account for the different concentrations of factor levels among various PCC formulations (Table 1). In a porcine model of dilutional coagulopathy, anesthetized pigs underwent $\mathrm{CPB}$ with hypothermia for 2 hours at $25^{\circ} \mathrm{C}$ followed by 1 hour of normothermia. After $\mathrm{CPB}$, the levels of factor II, VII, IX, and X were decreased from baseline by $32 \%$ to $48 \%$. Approximately 1 hour after $\mathrm{CPB}$, the pigs randomly received either isotonic saline $(1 \mathrm{~mL} / \mathrm{kg})$ or $30 \mathrm{IU} / \mathrm{kg}$ of 4F-PCCs (Beriplex P/N). ${ }^{30}$ In that study, the administration of PCCs led to overcorrection of these coagulation factor concentrations and reduced bleeding but did not display evidence of thromboembolism. ${ }^{30}$ Factor II levels have been shown to decrease to $~ 50 \%$ of normal after CPB in patients undergoing complex cardiac surgery. ${ }^{74}$ This is accompanied, however, by a similar decrease in anticoagulant factors (e.g., antithrombin III). Therefore, administering a dose of 4F-PCCs to achieve a $50 \%$ increase in factor II level may not be needed to ensure coagulation and could promote prothrombotic complications. $^{74}$ Similar to the use of initial INR values dictating PCC dosage administration for vitamin $\mathrm{K}$ antagonist reversal, ${ }_{11}^{11}$ laboratory data-driven algorithms for bleeding will, therefore, guide therapy in the perioperative realm.

In addition to other etiologies of bleeding experienced during cardiac surgery, extracorporeal flow of blood within a CPB circuit induces coagulopathy by dilution of procoagulants with circuit prime volume and activation of inflammatory cascades triggered by the exposure of blood components to the surface of these artificial conduits and other such diverse mechanisms. ${ }^{75,76}$ Thus, the resulting coagulopathy after $\mathrm{CPB}$ may be an amalgam of pre-existing procoagulant deficiencies compounded by this extracorporeal membrane exposure, intravascular volume expansion, consequences of inflammation, and organ ischemia-reperfusion injury. This is a unique feature of cardiac surgery, which increases predilection toward bleeding when compared with other types of operations. Small, retrospective studies have described using PCCs to correct warfarin-related hemorrhage after $\mathrm{CPB}^{77}$ by using the same INR, weight-based dosing algorithm previously described by Sarode et al. ${ }^{11}$ in nonsurgical patients. In a randomized, prospective, single-center study of 40 patients undergoing cardiac surgery, the use of 4-F PCCs (Cofact ${ }^{\circledR}$; Sanquin, Amsterdam, The Netherlands) was shown to be more effective than the use of FFP in the timely correction of INR and led to less frequent bleeding after surgery with less increase in cardiac filling pressures..$^{58}$ In addition, in a retrospective, propensity-matched study of patients undergoing pulmonary thromboendarterectomy for chronic thromboembolic pulmonary hypertension, increased blood loss was seen 12 hours after intensive care unit admission in the group of patients receiving FFP compared with PCCs (median [interquartile range], 650 [325-1075] $\mathrm{mL}$ vs 277 [175-608] mL, $P=0.008)$. No differences in clinical outcomes were noted. ${ }^{78}$

\section{Point-of-Care Testing}

Quantifying thrombin generation would likely provide the most accurate approach to determining the mechanism of post- $\mathrm{CPB}$ coagulopathy even before the onset of $\mathrm{CPB},{ }^{28}$ but there are currently no clinically available thrombin generation assays. However, several available point-of-care tests provide an estimation of thrombin generation that may be used for goal-directed hemostatic treatment of perioperative bleeding. Although point-of-care testing is not yet available in many hospitals, the importance of this technology should be discussed as it pertains to perioperative coagulopathic management. Briefly, both rotational thromboelastometry or ROTEM ${ }^{\circledR}$ (TEM International, Munich, Germany) and thromboelastography (TEG®; Haemonetics, Braintree, MA) are point-of-care devices that allow for the visual assessment of blood coagulation. The process of coagulation includes clot formation, propagation, stabilization, and clot dissolution. In the case of TEG, PCCs are indicated if $\mathrm{R}$ time (clot formation time) is prolonged, $\mathrm{K}$ time (occurrence of clot firmness) is prolonged, or $\alpha$ angle (kinetics of clot formation) is reduced. ${ }^{79}$ The newer version of TEG includes different assays, which allow for determination of PCC indication by using the RapidTEG ${ }^{\mathrm{TM}}$ (intrinsic and extrinsic activated assay), the kaolin TEG (intrinsic pathway-activated assay), and kaolin with heparinase (used with kaolin TEG and eliminates heparin effect). In the case of ROTEM, there are multiple assays that provide information regarding factor deficiencies in the clinical setting and include INTEM ${ }^{\circledR}$ (information similar to aPTT), EXTEM ${ }^{\circledR}$ (information similar to PT/INR), and HEPTEM ${ }^{\circledR}$ (contains heparinase to neutralize unfractionated heparin and used in conjunction with the INTEM reagent). When using these ROTEM assays, PCCs are indicated if the clotting time (CT) or clot firmness time is prolonged or if the $\alpha$ angle is reduced. ${ }^{79,80}$ The reader is directed to literature that comprehensively outlines the interpretation and technology regarding ROTEM and TEG forms of coagulation testing. ${ }^{79,80}$ The use of point-of-care-based transfusion algorithms, which include PCCs, has been suggested to reduce allogeneic blood transfusions. ${ }^{53,72,73}$ Allogeneic blood transfusions have demonstrated increased morbidity and mortality in several trials involving surgical and nonsurgical patients. ${ }^{81-85}$ Such an approach has been successfully implemented in the coagulation management related to cardiovascular surgery, and reduced allogeneic blood transfusions, FFP, and cryoprecipitate have been observed along with an increase in the administration of fibrinogen concentrate and PCCs. ${ }^{53}$

More recently, an observational study of 25 patients found that the administration of aPCCs (FEIBA) for refractory bleeding after complex cardiac surgery reduced the frequency of FFP and platelet transfusions. ${ }^{86}$ Point-of-care laboratory testing was performed after FFP administration and again after aPCCs. FEIBA was more effective at normalizing INR compared with FFP without evidence for thromboembolism. ${ }^{86}$

In a single-center, retrospective analysis of patients undergoing cardiac surgery, implementation of a coagulation management algorithm based on point-of-care testing (ROTEM) using first-line therapy with coagulation factor concentrates (including 4F-PCCs) was associated with reduced allogeneic blood transfusions and decreased thromboembolic events compared with historical controls..$^{53}$ In this study, 20 to $25 \mathrm{IU} / \mathrm{kg}$ 4F-PCCs were administered in case of severe, diffuse bleeding after heparin reversal if EXTEM CT was $>90$ seconds, and 35 to $40 \mathrm{IU} / \mathrm{kg} 4 \mathrm{~F}-\mathrm{PCCs}$ 
were administered if CT was $>100$ seconds. ${ }^{53}$ Improved outcomes were not demonstrated after the institutional implementation of this algorithm, but this study may have been limited by using historical controls that included fewer emergency cases and less complex procedures when compared with the contemporary cohort. ${ }^{53}$ Thoracic aortic operations requiring hypothermic circulatory arrest are a category of cardiothoracic surgery, which often require multiple transfusions of blood products, procoagulants, and factor concentrates after separation from $\mathrm{CPB} .{ }^{87}$ The use of ROTEM in a single-center, prospective, randomized trial $(n=56)$ was noted to reduce the transfusion of allogeneic blood (9 vs 16 units; $P=0.02$ ) when compared with standard management of coagulopathy in patients undergoing thoracic aortic surgery with hypothermic circulatory arrest. ${ }^{88}$ Improved outcomes and reduced transfusion of allogeneic blood products were found in another study using 20 to $30 \mathrm{IU} / \mathrm{kg}$ 4F-PCCs (PPSB®; CAF-DCF, Brussels, Belgium) as a part of another ROTEM-directed transfusion algorithm. ${ }^{73}$

\section{General Surgery, Hepatic Injury, and Liver Transplantation}

Literature related to the administration of PCCs during noncardiac surgery for perioperative bleeding is mainly related to vitamin $\mathrm{K}$ antagonist reversal or supplementation of factors in the setting of liver failure. In a single-center, retrospective, observational study, the use of 4F-PCCs (Beriplex®) was observed among 2 groups of patients: (1) those requiring reversal of warfarin for increased INR or in preparation for urgent/emergent surgery; and 2) those needing treatment of severe diffuse perioperative bleeding but not on preoperative warfarin. ${ }^{89}$ The administration of 4F-PCCs resulted in correction of abnormal INR in the 12 nonsurgical patients $(P<0.001)$, and correction of diffuse bleeding was observed in 26 of 27 surgical patients (96\%). ${ }^{89}$ No thromboembolic events were observed in either group.

There is a paucity of research regarding the impact of PCCs on perioperative and nonsurgical bleeding in patients with hepatic failure. ${ }^{90}$ Animal studies with bleeding after induced liver injury, however, have shown promise regarding the beneficial impact of PCCs. In a laboratory study using a porcine model of blunt liver injury, induced coagulopathy, and hemodynamic instability related to bleeding, 27 anesthetized pigs displayed improved hemodynamics, increased thrombin generation, and correction of abnormal INR and EXTEM values (namely CT and clot firmness time) after 4F-PCCs (low-dose group: $35 \mathrm{IU} / \mathrm{kg}$ ) when compared with saline. Two animals in the saline group had a singular lung arteriole thromboembolus of 1 to $2 \mathrm{~mm}$ in diameter, whereas 3 animals from the lower PCC dosing group had several thromboemboli each measuring 1 to $2 \mathrm{~mm}$ in diameter. ${ }^{91}$ Interestingly in those receiving higher doses of PCCs (50 IU/kg), disseminated intravascular coagulation was observed based on the International Society of Thrombosis and Hemostasis criteria, ${ }^{92}$ and all of these animals contained $>4 \mathrm{~mm}$ of multiple lung arteriole thromboembolisms on autopsy. In addition, a net-like fibrinogen deposition was noted in the lung capillaries of the higher dosage group, which was present but not as well developed in the control and low-dosage animals. ${ }^{91}$ In an ongoing multicenter, randomized, controlled trial from The Netherlands, the utility of 4F-PCCs (Cofact) is being studied with respect to reducing allogeneic red blood cell transfusions during orthotopic liver transplantation in cirrhotic patients with INR $\geq 1.5$ (PROTON Trial; Netherlands Trial Register: 3174). ${ }^{93}$

\section{Trauma-Related Bleeding and Intracranial Hemorrhage}

There have been several reports on the use of PCC s in trauma patients. ${ }^{94,95}$ In a retrospective, observational single-center study of 45 trauma patients, 3F-PCCs (Profilnine®; Grifols Biologicals, Los Angeles, CA) reversed clinical bleeding and INR to $\leq 1.5$ at a mean dose of $25 \mathrm{IU} / \mathrm{kg}$ in both warfarin $(n=25, P \leq 0.001)$ and nonwarfarin $(n=20, P \leq 0.001)$ groups. ${ }^{96}$ Both groups experienced refractory bleeding after receiving plasma. ${ }^{96}$ The primary anatomic site of injury was intracranial $(68 \%$ of patients in the preoperative warfarin group and $40 \%$ in the nonwarfarin group). Mortality was $28 \%$ among the preoperative warfarin group and $40 \%$ among those patients who did not receive warfarin before injury. ${ }^{96}$

Point-of-care coagulation testing has also been used in human studies related to bleeding in adult trauma patients requiring reversal of vitamin $\mathrm{K}$ antagonist-induced coagulopathy; improvement in hemostatic efficacy after PCC administration has been illustrated. ${ }^{97-99}$ PCCs were administered in 1 retrospective analysis of 131 trauma patients who received $\geq 5$ units of packed red blood cells within 24 hours as a part of a factor concentrate-driven, multimodal, coagulation management algorithm using ROTEM guidance. The survival benefit of this approach was determined by predicted mortality modeling in the population compared with actual observed mortality. ${ }^{98}$ In this study, fibrinogen concentrate was given if maximum clot firmness was low on FIBTEM $\AA$, which is the ROTEM assay measure of fibrinogen activity. PCCs were then administered in case of recent warfarin intake or CT $>1.5$ times normal on EXTEM. Lack of improvement of maximum clot firmness on EXTEM after fibrinogen concentrate and PCCs was an indication for platelet concentrate. The authors reported a $14 \%$ observed mortality compared with $28 \%$ predicted mortality $(P=0.0018) .{ }^{98}$ PCCs may be administered in trauma patients at varying doses based on CT prolongation. ${ }^{99,100}$ A prevailing theme has evolved whereby using initial INR and/or EXTEM CT may provide a basis for initial dosing. ${ }^{11,53,72,73,100}$

Administration of PCCs has been used in the reversal of coagulopathy and control of intracranial hemorrhage. In a prospective, observational single-center study involving 33 patients, emergent reversal of coagulopathy was observed after administration of 4F-PCCs (KCentra). In that study, a mean dose of 2200 IU (range, 1500-2500 IU) of PCCs led to a faster correction of an abnormal INR $(<1.4)$ compared with FFP (65 vs 256 minutes, $P<0.05) .{ }^{57}$ Kerebel et al. performed a phase III, prospective, randomized, openlabel study of 59 patients with warfarin-associated intracranial hemorrhage involving 22 centers. The patients received either $25 \mathrm{IU} / \mathrm{kg}(n=29)$ or $40 \mathrm{IU} / \mathrm{kg}(n=30)$ of $4 \mathrm{~F}-\mathrm{PCC}$ (Octaplex®; Octapharma, Vienna, Austria). ${ }^{101}$ Despite more rapid reversal of INR and normalization of factors II and X and proteins $C$ and $S$ concentrations, there was no difference in hematoma volume $(P=0.71)$, clinical $(P=0.73)$ or neurologic outcomes $(P=0.83)$ as well as thromboembolic 
events $(P=1.0)$ between the 2 groups. ${ }^{101}$ In contrast, use of rFVIIa in this patient population was associated with an increased incidence of thromboembolic events in the $80-\mu \mathrm{g} / \mathrm{kg}$ treatment group without benefit in clinical outcomes. ${ }^{102-106}$ There are no data to describe or support the use of PCCs in patients with normal coagulation profiles, but similar thromboembolic complications may be anticipated. ${ }^{1}$

\section{F-PCCs Versus 4F-PCCs}

There are increasing reports comparing the safety and efficacy of both 3F- and 4F-PCCs that deserve particular attention. Special consideration to the importance of one composition containing appreciable amounts of anticoagulants may further contribute to the overall safety and efficacy of 4F-PCC solutions. ${ }^{107}$ In a case report, massive intracardiac and aortic thrombus formation was noted by emergency transesophageal echocardiography after administration of $50 \mathrm{IU} / \mathrm{kg}$ of 3F-PCCs (Profilnine) for warfarin reversal (initial INR, 5.5) before urgent spine surgery with an indwelling mechanical mitral valve. ${ }^{108}$ Thromboembolism was likely because of the higher dosage of PCCs, the higher concentration of factor II present in Profilnine compared with KCentra (Table 1; 150 vs 130 IU, respectively, per $100 \mathrm{IU}$ of PCCs) and the absence of anticoagulants in Profilnine, which may otherwise be present in FFP and to a certain degree in 4F-PCCs (KCentra). In a meta-analysis of 18 studies (12 prospective and 6 retrospective) involving 654 elderly patients presenting for emergent warfarin reversal, INR was corrected in 75\% of patients after 3F-PCC administration and in $92 \%$ of patients after 4F-PCCs. ${ }^{109}$ Eightyone patients receiving either low-dose 3F-PCCs (profilnine, $25 \mathrm{IU} / \mathrm{kg}$ ) or high-dose 3F-PCCs (50 IU/kg) were compared against patients who had received FFP for supratherapeutic INR and warfarin reversal. Administering FFP alone (3.6 units [range, 2-8 units]) corrected the initial INR from 9.4 (range, 5.1-9.4) to 2.3 (range, 1.2-5.0). 3F-PCCs were able to reduce initial INR in both the low-dose group (initial INR, 9.0 [range, 5.2-15.0] to INR, 4.6 [range, 1.4-15.0]) and high-dose group (initial INR, 8.6 [range, 5.3-15.0] to INR, 4.7 [range, 1.4-15.0]), but complete correction to an INR $<1.5$ was not achieved without additional FFP. Although these study results support the sensitivity of INR to factor VII levels, INR values in this increased range may also reflect clinically relevant bleeding or potential for bleeding, which were not evaluated in this study. ${ }^{9}$

\section{PCCs for Reversal of Direct Oral Anticoagulants}

There are increasing data regarding the use of PCCs for the management of bleeding related to direct oral anticoagulants, including the direct thrombin inhibitor dabigatran (Pradaxa ${ }^{\circ}$; Boehringer Ingelheim, Ridgefield, $\mathrm{CT}$ ) and factor $\mathrm{Xa}$ inhibitors (e.g., rivaroxaban, apixaban, edoxaban). ${ }^{110,111}$ A recent volunteer study compared the effects of 3F-PCCs (Profilnine) with 4F-PCCs (Beriplex $\mathrm{P} / \mathrm{N}$ ) on $\mathrm{PT}$, thrombin generation, aPTT, and antifactor Xa activity of rivaroxaban. ${ }^{112}$ Volunteers received $50 \mathrm{IU} /$ $\mathrm{kg}$ of 3F-PCCs $(n=12)$, 4F-PCCs $(n=10)$, or saline $(n=12)$. The better response of thrombin generation to 3F-PCCs was likely reflective of the higher factor II concentration in Profilnine compared with Beriplex (Table 1). In another study, $50 \mathrm{IU} / \mathrm{kg}$ 4F-PCCs (Cofact) was given to healthy male volunteers treated with rivaroxaban $(n=6)$ or dabigatran $(n=6) .{ }^{113}$ Normalization of thrombin generation was seen in rivaroxaban-treated subjects but not those treated with dabigatran. This is consistent with in vitro, TEG evidence that PCCs are not able to reverse the coagulopathic effects of dabigatran in healthy volunteers. ${ }^{114}$

Observational studies evaluating the use of PCCs in the treatment of coagulopathy related to the direct factor Xa inhibitors suggest that these compounds are able to reverse the anticoagulant effects by increasing the production of prothrombinase, thereby leading to thrombin generation (Fig. 3). Conversely, direct thrombin inhibitors impact fibrin production downstream from where PCCs may have the most impact. This proposed mechanism is supported by available data, which suggest that PCCs may not be effective in treating direct thrombin inhibitor-related coagulopathy. aPCCs (FEIBA), on the other hand, have shown efficacy in dabigatran-associated intracranial bleeding in a single-case study. ${ }^{115}$ Safety concerns related to thrombotic risk in experimental models, however, persist regarding the fact that procoagulant effects of aPCCs (because of variable

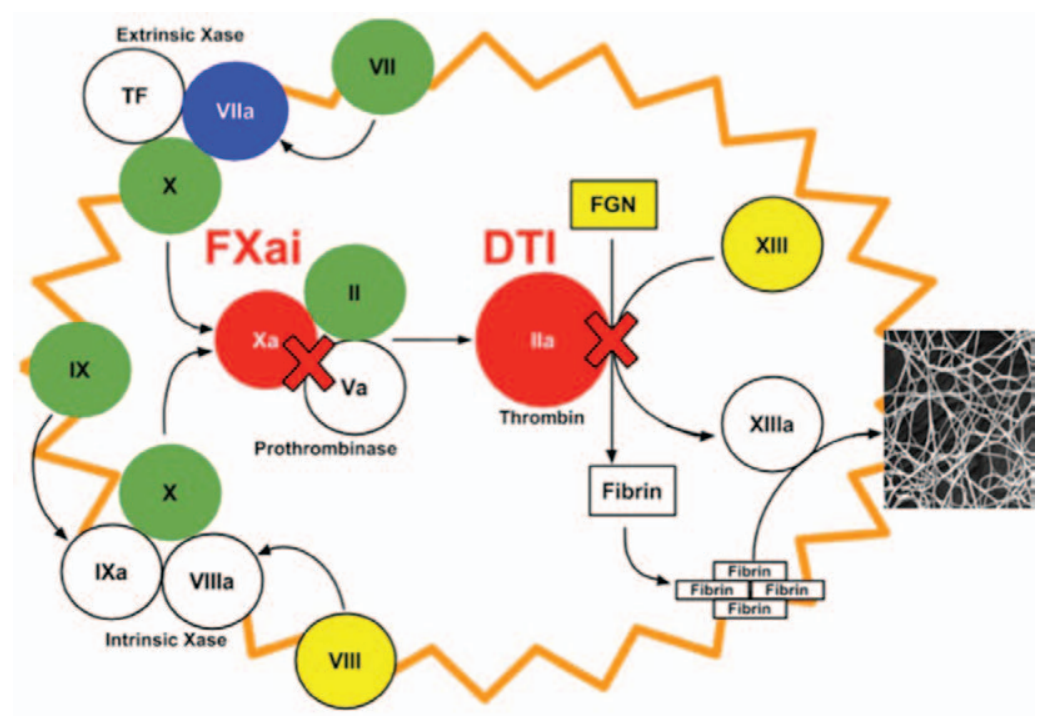

Figure 3. Reduced coagulation factor concentrations because of direct oral anticoagulants: direct thrombin inhibitors and factor Xa inhibitors. Factor $\mathrm{Xa}$ inhibitors directly reduce factor $\mathrm{Xa}$ activity and indirectly reduce thrombin generation (downstream). Direct thrombin inhibitors, as the name implies, directly inhibit factor lla production and block downstream fibrin stabilization (scanning electron micrographic image insert of weak fibrin cross-linkage). $\mathrm{DTI}=$ direct thrombin inhibitor; FGN = fibrinogen; FXai = factor Xa inhibitor; $\mathrm{TF}=$ tissue factor; Xase $=$ tenase 
amounts of activated factors; Table 1) may outlast the duration of action of dabigatran. ${ }^{116}$

Although PCCs are, currently, an important therapeutic consideration to reverse direct oral anticoagulant-related bleeding, discussion of additional therapeutic strategies for specific reversal is prudent. Reversal agents are relevant because of the longer half-life of PCCs compared with direct oral anticoagulants and the potential for thromboembolism should PCCs be administered for coagulopathy reversal. These reversal agents include idarucizumab (Praxbind®; Boehringer Ingelheim) for dabigatran, ${ }^{117}$ Andexanet alfa (Portola Pharmaceuticals, San Francisco, CA) for factor $\mathrm{Xa}$ inhibitors, ${ }^{118,119}$ and Ciraparantag (PER977®; Perisphere Inc., Danbury, CT) for dabigatran and the factor Xa inhibitors. ${ }^{120,121}$ Idarucizumab, a humanized monoclonal antibody fragment, ${ }^{122}$ binds dabigatran with an affinity 350 times that of thrombin and, therefore, binds to both free dabigatran and dabigatran bound to thrombin, rendering the drug inactive. ${ }^{123}$ Idarucizumab has recently received FDA approval for use in patients who are receiving dabigatran during emergency situations when there is a need to reverse coagulopathy related to the direct thrombin inhibitor (www.fda.gov, accessed October 16, 2015). Andexanet alfa is a recombinant protein analog of factor $\mathrm{X}$ a that binds to factor $\mathrm{X}$ a inhibitors and antithrombin but does not trigger prothrombotic activity. ${ }^{119}$ This drug is in phase $3 b-4 a$ trials at the time of this writing (NCT02329327). ${ }^{111}$ Ciraparantag is a small synthetic molecule that competitively binds the direct oral anticoagulants, restoring the activity of blocked coagulation factors. Currently, this agent is in phase 2 studies evaluating its efficacy in healthy volunteers receiving edoxaban (NCT02207257). Despite the potential for future specific reversal agents, a multimodal approach to hemostatic resuscitation is still required during direct oral anticoagulant-related hemorrhage, which may include PCCs to restore deficient factor levels.

\section{Thromboembolism and Off-Label Use of PCCs}

Using PCCs beyond the approved use of vitamin K antagonist reversal warrants emphasis regarding the potential for thromboembolism. Prothrombotic risk is increased with repeat or excessive dosing because of promotion of thrombin generation and therefore fibrin crosslinkage (Fig. 1). Prothrombin/factor II levels are directly related to thrombin generation, and therefore, increasing serum factor II concentrations will lead to increased thrombin generation. The use of PCCs may be warranted in clinical scenarios in which factor II concentrations are reduced such as from hemodilution or direct consumption from continuous bleeding. In other scenarios, activated factor concentrates (aPCCs or rFVIIa) may be required to bypass inhibitor activity despite normal factor II levels, as seen in hemophiliacs. Higher dose administration of PCCs (>25 IU $/ \mathrm{kg}$ ) in the reversal of factor Xa inhibitors may lead to thrombosis, for example, because the effects of both apixaban and rivaroxaban dissipate in $<24$ hours (assuming normal renal function), whereas factor II levels will remain increased for $\geq 48$ hours. Close attention to mechanical and/or pharmacologic thromboprophylaxis is warranted when these longer acting factor concentrates are used to treat a brief period of intraoperative or drugrelated coagulopathy.

\section{CONCLUSIONS}

PCCs have recently entered the perioperative setting for the off-label indication of diffuse coagulopathy without a vascular source for bleeding. Evidence thus far for the safe and effective use of PCCs is limited to retrospective, observational studies and historical controls. Clinicians managing patients with perioperative bleeding should have an understanding of the mechanisms by which PCCs impact the coagulation cascade and the importance of a multimodal approach to the management of diffuse bleeding related to surgery. Correction of hypofibrinogenemia and thrombocytopenia before the administration of PCCs may be prudent to maximize the efficacy of lower PCC dosing and to minimize the risk for adverse thromboembolic events. Lessons from the higher dosing of rFVIIa in nonhemophiliac surgical patients should be incorporated into the advent of perioperative PCC use to help avoid such events. Administration should be based on clinically observed bleeding as well as laboratory and point-of-care data incorporated into an institutionally derived approach to coagulopathic management. In addition, prospective, randomized controlled trials are needed to evaluate the off-label use of PCCs in this setting. IH

\section{DISCLOSURES}

Name: Kamrouz Ghadimi, MD.

Contribution: This author helped perform the literature search and prepare the manuscript.

Attestation: Kamrouz Ghadimi approved the final manuscript. Conflicts of Interest: Kamrouz Ghadimi is a coinvestigator in a prospective, open-label study of Andexanet-Alfa in patients receiving factor Xa inhibitors with acute major bleeding, sponsored by Portola Pharmaceuticals.

Name: Jerrold H. Levy, MD, FAHA, FCCM.

Contribution: This author helped prepare the manuscript.

Attestation: Jerrold H. Levy approved the final manuscript.

Conflicts of Interest: Jerrold H. Levy serves on steering committees for Boehringer-Ingelheim, CSL Behring, Grifols, and Janssen; he is a consultant to Instrumentation Laboratories.

Name: Ian J. Welsby, BSc, MBBS, FRCA.

Contribution: This author helped perform the literature search and prepare the manuscript.

Attestation: Ian J. Welsby approved the final manuscript.

Conflicts of Interest: Ian J. Welsby is the principal investigator in a prospective, open-label study of Andexanet Alfa in patients receiving factor Xa inhibitors with acute major bleeding, sponsored by Portola Pharmaceuticals, and has recently received grant support from CSL Behring and Terumo BCT.

This manuscript was handled by: Charles W. Hogue, MD.

\section{ACKNOWLEDGMENTS}

The authors thank Dr. Oluwatoyosi A. Onwuemene, MD, Assistant Professor of Medicine, Division of Hematology, Duke University Medical Center, for help in contributing to the schematic figures illustrated in this article.

\section{REFERENCES}

1. Sørensen B, Spahn DR, Innerhofer P, Spannagl M, Rossaint R. Clinical review: prothrombin complex concentrates-evaluation of safety and thrombogenicity. Crit Care 2011;15:201 
2. Key NS, Negrier C. Coagulation factor concentrates: past, present, and future. Lancet 2007;370:439-48

3. Negrier C, Gomperts E, Oldenburg J. The history of FEIBA: a lifetime of success in the treatment of haemophilia complicated by an inhibitor. Haemophilia 2006;12:4-13

4. Lin Y, Stanworth S, Birchall J, Doree C, Hyde C. Recombinant factor VIIa for the prevention and treatment of bleeding in patients without haemophilia. Cochrane Database Syst Rev 2011;3:CD005011.

5. Simpson E, Lin Y, Stanworth S, Birchall J, Doree C, Hyde C. Recombinant factor VIIa for the prevention and treatment of bleeding in patients without haemophilia. Cochrane Database Syst Rev 2012;3:CD005011

6. Xi M, Béguin S, Hemker HC. The relative importance of the factors II, VII, IX and X for the prothrombinase activity in plasma of orally anticoagulated patients. Thromb Haemost 1989;62:788-91

7. Imberti D, Barillari G, Biasioli C, Bianchi M, Contino L, Duce R, D'Incà M, Gnani MC, Mari E, Ageno W. Emergency reversal of anticoagulation with a three-factor prothrombin complex concentrate in patients with intracranial haemorrhage. Blood Transfus 2011;9:148-55

8. Choi Q, Kim JE, Hyun J, Han KS, Kim HK. Contributions of procoagulants and anticoagulants to the international normalized ratio and thrombin generation assay in patients treated with warfarin: potential role of protein $\mathrm{Z}$ as a powerful determinant of coagulation assays. Thromb Res 2013;132:e70-5

9. Holland L, Warkentin TE, Refaai M, Crowther MA, Johnston MA, Sarode R. Suboptimal effect of a three-factor prothrombin complex concentrate (Profilnine-SD) in correcting supratherapeutic international normalized ratio due to warfarin overdose. Transfusion 2009;49:1171-7

10. Dzik WS. Reversal of drug-induced anticoagulation: old solutions and new problems. Transfusion 2012;52(suppl 1):45S-55S

11. Sarode R, Milling TJ Jr, Refaai MA, Mangione A, Schneider A, Durn BL, Goldstein JN. Efficacy and safety of a 4-factor prothrombin complex concentrate in patients on vitamin $\mathrm{K}$ antagonists presenting with major bleeding: a randomized, plasma-controlled, phase IIIb study. Circulation 2013;128:1234-43

12. Tanaka KA, Szlam F, Dickneite G, Levy JH. Effects of prothrombin complex concentrate and recombinant activated factor VII on vitamin $\mathrm{K}$ antagonist induced anticoagulation. Thromb Res 2008;122:117-23

13. Allen GA, Wolberg AS, Oliver JA, Hoffman M, Roberts HR, Monroe DM. Impact of procoagulant concentration on rate, peak and total thrombin generation in a model system. J Thromb Haemost 2004;2:402-13

14. Thompson CA, Kyle R, Gertz M, Heit J, Pruthi R, Pardanani A. Systemic AL amyloidosis with acquired factor X deficiency: a study of perioperative bleeding risk and treatment outcomes in 60 patients. Am J Hematol 2010;85:171-3

15. Monroe DM, Hoffman M, Roberts HR. Platelets and thrombin generation. Arterioscler Thromb Vasc Biol 2002;22:1381-9

16. Kumar R, Béguin S, Hemker HC. The influence of fibrinogen and fibrin on thrombin generation-evidence for feedback activation of the clotting system by clot bound thrombin. Thromb Haemost 1994;72:713-21

17. Roberts HR, Hoffman M, Monroe DM. A cell-based model of thrombin generation. Semin Thromb Hemost 2006;32(suppl 1):32-8

18. Levy JH, Szlam F, Tanaka KA, Sniecienski RM. Fibrinogen and hemostasis: a primary hemostatic target for the management of acquired bleeding. Anesth Analg 2012;114:261-74

19. Hiippala ST, Myllylä GJ, Vahtera EM. Hemostatic factors and replacement of major blood loss with plasma-poor red cell concentrates. Anesth Analg 1995;81:360-5

20. Ranucci M, Baryshnikova E, Crapelli GB, Rahe-Meyer N, Menicanti L, Frigiola A; Surgical Clinical Outcome REsearch (SCORE) Group. Randomized, double-blinded, placebo-controlled trial of fibrinogen concentrate supplementation after complex cardiac surgery. J Am Heart Assoc 2015;4:e002066

21. Karkouti K, Beattie WS, Arellano R, Aye T, Bussieres JS, Callum JL, Cheng D, Heinrich L, Kent B, Lee TW, MacAdams C, Mazer
CD, Muirhead B, Rochon AG, Rubens FD, Sawchuk C, Wang S, Waters T, Wong BI, Yau TM. Comprehensive Canadian review of the off-label use of recombinant activated factor VII in cardiac surgery. Circulation 2008;118:331-8

22. Lee AI, Campigotto F, Rawn JD, Neuberg D, Kaufman RM, Berliner N. Clinical significance of coagulation studies in predicting response to activated recombinant factor VII in cardiac surgery patients. Br J Haematol 2012;157:397-400

23. Hemker HC, Al Dieri R, De Smedt E, Béguin S. Thrombin generation, a function test of the haemostatic-thrombotic system. Thromb Haemost 2006;96:553-61

24. Hemker HC, Giesen P, AlDieri R, Regnault V, de Smed E, Wagenvoord R, Lecompte T, Béguin S. The calibrated automated thrombogram (CAT): a universal routine test for hyper- and hypocoagulability. Pathophysiol Haemost Thromb 2002;32:249-53

25. Machlus KR, Colby EA, Wu JR, Koch GG, Key NS, Wolberg AS. Effects of tissue factor, thrombomodulin and elevated clotting factor levels on thrombin generation in the calibrated automated thrombogram. Thromb Haemost 2009;102:936-44

26. Dargaud Y, Béguin S, Lienhart A, Al Dieri R, Trzeciak C, Bordet JC, Hemker HC, Negrier C. Evaluation of thrombin generating capacity in plasma from patients with haemophilia A and B. Thromb Haemost 2005;93:475-80

27. Al Dieri R, Peyvandi F, Santagostino E, Giansily M, Mannucci PM, Schved JF, Béguin S, Hemker HC. The thrombogram in rare inherited coagulation disorders: its relation to clinical bleeding. Thromb Haemost 2002;88:576-82

28. Bosch $Y, A l$ Dieri $R$, ten Cate $H$, Nelemans $P$, Bloemen $S$, Hemker C, Weerwind P, Maessen J, Mochtar B. Preoperative thrombin generation is predictive for the risk of blood loss after cardiac surgery: a research article. J Cardiothorac Surg 2013;8:154

29. Guzzetta NA, Szlam F, Kiser AS, Fernandez JD, Szlam AD, Leong $\mathrm{T}$, Tanaka KA. Augmentation of thrombin generation in neonates undergoing cardiopulmonary bypass. Br J Anaesth 2014;112:319-27

30. Kaspereit F, Hoffmann S, Pragst I, Dickneite G. Prothrombin complex concentrate mitigates diffuse bleeding after cardiopulmonary bypass in a porcine model. Br J Anaesth 2010;105:576-82

31. Ay C, Dunkler D, Simanek R, Thaler J, Koder S, Marosi C, Zielinski C, Pabinger I. Prediction of venous thromboembolism in patients with cancer by measuring thrombin generation: results from the Vienna Cancer and Thrombosis Study. J Clin Oncol 2011;29:2099-103

32. Hron G, Kollars M, Binder BR, Eichinger S, Kyrle PA. Identification of patients at low risk for recurrent venous thromboembolism by measuring thrombin generation. JAMA 2006;296:397-402

33. Lutsey PL, Folsom AR, Heckbert SR, Cushman M. Peak thrombin generation and subsequent venous thromboembolism: the Longitudinal Investigation of Thromboembolism Etiology (LITE) study. J Thromb Haemost 2009;7:1639-48

34. Gatt A, Riddell A, van Veen JJ, Kitchen S, Tuddenham EG, Makris M. Optimizing warfarin reversal-an ex vivo study. J Thromb Haemost 2009;7:1123-7

35. Levy JH, Tanaka KA, Dietrich W. Perioperative hemostatic management of patients treated with vitamin $\mathrm{K}$ antagonists. Anesthesiology 2008;109:918-26

36. Pernod G, Godiér A, Gozalo C, Tremey B, Sié P; French National Authority for Health. French clinical practice guidelines on the management of patients on vitamin $\mathrm{K}$ antagonists in at-risk situations (overdose, risk of bleeding, and active bleeding). Thromb Res 2010;126:e167-74

37. Karkouti K, McCluskey SA, Syed S, Pazaratz C, Poonawala H, Crowther MA. The influence of perioperative coagulation status on postoperative blood loss in complex cardiac surgery: a prospective observational study. Anesth Analg 2010;110:1533-40

38. Sniecinski R, Szlam F, Chen EP, Bader SO, Levy JH, Tanaka KA. Antithrombin deficiency increases thrombin activity after prolonged cardiopulmonary bypass. Anesth Analg 2008;106:713-8

39. Coakley M, Hall JE, Evans C, Duff E, Billing V, Yang L, McPherson D, Stephens E, Macartney N, Wilkes AR, Collins PW. Assessment of thrombin generation measured before and after cardiopulmonary bypass surgery and its association with postoperative bleeding. J Thromb Haemost 2011;9:282-92 
40. Russo C, Girelli D, Olivieri O, Guarini P, Manzato F, Pizzolo F, Zaia B, Mazzucco A, Corrocher R. G20210A prothrombin gene polymorphism and prothrombin activity in subjects with or without angiographically documented coronary artery disease. Circulation 2001;103:2436-40

41. Faraoni D, Fenger-Eriksen C, Gillard S, Willems A, Levy JH, Van der Linden P. Evaluation of dynamic parameters of thrombus formation measured on whole blood using rotational thromboelastometry in children undergoing cardiac surgery: a descriptive study. Paediatr Anaesth 2015;25:573-9

42. Baglin TP, Keeling DM, Watson HG; British Committee for Standards in Haematology. Guidelines on oral anticoagulation (warfarin): third edition-2005 update. Br J Haematol 2006;132:277-85

43. Baker RI, Coughlin PB, Gallus AS, Harper PL, Salem HH, Wood EM; Warfarin Reversal Consensus Group. Warfarin reversal: consensus guidelines, on behalf of the Australasian Society of Thrombosis and Haemostasis. Med J Aust 2004;181:492-7

44. Ferraris VA, Brown JR, Despotis GJ, Hammon JW, Reece TB, Saha SP, Song HK, Clough ER, Shore-Lesserson LJ, Goodnough LT, Mazer CD, Shander A, Stafford-Smith M, Waters J, Baker RA, Dickinson TA, FitzGerald DJ, Likosky DS, Shann KG. 2011 update to the Society of Thoracic Surgeons and the Society of Cardiovascular Anesthesiologists blood conservation clinical practice guidelines. Ann Thorac Surg 2011;91:944-82

45. Holbrook A, Schulman S, Witt DM, Vandvik PO, Fish J, Kovacs MJ, Svensson PJ, Veenstra DL, Crowther M, Guyatt GH; American College of Chest Physicians. Evidence-based management of anticoagulant therapy: Antithrombotic Therapy and Prevention of Thrombosis, 9th ed: American College of Chest Physicians Evidence-Based Clinical Practice Guidelines. Chest 2012;141:e152S-84S

46. Leissinger CA, Blatt PM, Hoots WK, Ewenstein B. Role of prothrombin complex concentrates in reversing warfarin anticoagulation: a review of the literature. Am J Hematol 2008;83:137-43

47. Spahn DR, Bouillon B, Cerny V, Coats TJ, Duranteau J, Fernández-Mondéjar E, Filipescu D, Hunt BJ, Komadina R, Nardi G, Neugebauer E, Ozier Y, Riddez L, Schultz A, Vincent JL, Rossaint R. Management of bleeding and coagulopathy following major trauma: an updated European guideline. Crit Care 2013;17:R76

48. Ansell J, Hirsh J, Hylek E, Jacobson A, Crowther M, Palareti G; American College of Chest Physicians. Pharmacology and management of the vitamin K antagonists: American College of Chest Physicians Evidence-Based Clinical Practice Guidelines (8th Edition). Chest 2008;133:160S-98S

49. Morgenstern LB, Hemphill JC III, Anderson C, Becker K, Broderick JP, Connolly ES Jr, Greenberg SM, Huang JN, MacDonald RL, Messé SR, Mitchell PH, Selim M, Tamargo RJ; American Heart Association Stroke Council and Council on Cardiovascular Nursing. Guidelines for the management of spontaneous intracerebral hemorrhage: a guideline for healthcare professionals from the American Heart Association/ American Stroke Association. Stroke 2010;41:2108-29

50. Dzik WH, Blajchman MA, Fergusson D, Hameed M, Henry B, Kirkpatrick AW, Korogyi T, Logsetty S, Skeate RC, Stanworth S, MacAdams C, Muirhead B. Clinical review: Canadian National Advisory Committee on Blood and Blood Products-Massive transfusion consensus conference 2011: report of the panel. Crit Care 2011;15:242-54

51. Steiner T, Kaste M, Forsting M, Mendelow D, Kwiecinski $H$, Szikora I, Juvela S, Marchel A, Chapot R, Cognard C, Unterberg A, Hacke W. Recommendations for the management of intracranial haemorrhage-part I: spontaneous intracerebral haemorrhage. The European Stroke Initiative Writing Committee and the Writing Committee for the EUSI Executive Committee. Cerebrovasc Dis 2006;22:294-316

52. American Society of Anesthesiologists Task Force on Perioperative Blood Management. Practice guidelines for perioperative blood management: an updated report by the American Society of Anesthesiologists Task Force on Perioperative Blood Management*. Anesthesiology 2015;122:241-75

53. Görlinger K, Dirkmann D, Hanke AA, Kamler M, Kottenberg E, Thielmann M, Jakob H, Peters J. First-line therapy with coagulation factor concentrates combined with point-of-care coagulation testing is associated with decreased allogeneic blood transfusion in cardiovascular surgery: a retrospective, single-center cohort study. Anesthesiology 2011;115:1179-91

54. Franchini M, Lippi G. Prothrombin complex concentrates: an update. Blood Transfus 2010;8:149-54

55. Lankiewicz MW, Hays J, Friedman KD, Tinkoff G, Blatt PM. Urgent reversal of warfarin with prothrombin complex concentrate. J Thromb Haemost 2006;4:967-70

56. Pabinger I, Tiede A, Kalina U, Knaub S, Germann R, Ostermann H; Beriplex P/N Anticoagulation Reversal Study Group. Impact of infusion speed on the safety and effectiveness of prothrombin complex concentrate: a prospective clinical trial of emergency anticoagulation reversal. Ann Hematol 2010;89:309-16

57. Yanamadala V, Walcott BP, Fecci PE, Rozman P, Kumar JI, Nahed BV, Swearingen B. Reversal of warfarin associated coagulopathy with 4 -factor prothrombin complex concentrate in traumatic brain injury and intracranial hemorrhage. J Clin Neurosci 2014;21:1881-4

58. Demeyere R, Gillardin S, Arnout J, Strengers PF. Comparison of fresh frozen plasma and prothrombin complex concentrate for the reversal of oral anticoagulants in patients undergoing cardiopulmonary bypass surgery: a randomized study. Vox Sang 2010;99:251-60

59. Meehan R, Tavares M, Sweeney J. Clinical experience with oral versus intravenous vitamin $\mathrm{K}$ for warfarin reversal. Transfusion 2013;53:491-8

60. Turecek PL, Váradi K, Gritsch H, Schwarz HP. FEIBA: mode of action. Haemophilia 2004;10(suppl 2):3-9

61. Wójcik C, Schymik ML, Cure EG. Activated prothrombin complex concentrate factor VIII inhibitor bypassing activity (FEIBA) for the reversal of warfarin-induced coagulopathy. Int J Emerg Med 2009;2:217-25

62. Levi M, Levy JH, Andersen HF, Truloff D. Safety of recombinant activated factor VII in randomized clinical trials. N Engl J Med 2010;363:1791-800

63. Mathijssen NC, Masereeuw R, Holme PA, van Kraaij MG, Laros-van Gorkom BA, Peyvandi F, van Heerde WL. Increased volume of distribution for recombinant activated factor VII and longer plasma-derived factor VII half-life may explain their long lasting prophylactic effect. Thromb Res 2013;132:256-62

64. Andersen ND, Bhattacharya SD, Williams JB, Fosbol EL, Lockhart EL, Patel MB, Gaca JG, Welsby IJ, Hughes GC. Intraoperative use of low-dose recombinant activated factor VII during thoracic aortic operations. Ann Thorac Surg 2012;93:1921-8

65. Hacquard M, Durand M, Lecompte T, Boini S, Briançon S, Carteaux JP. Off-label use of recombinant activated factor VII in intractable haemorrhage after cardiovascular surgery: an observational study of practices in 23 French cardiac centres (2005-7). Eur J Cardiothorac Surg 2011;40:1320-7

66. Gill R, Herbertson M, Vuylsteke A, Olsen PS, von Heymann C, Mythen M, Sellke F, Booth F, Schmidt TA. Safety and efficacy of recombinant activated factor VII: a randomized placebocontrolled trial in the setting of bleeding after cardiac surgery. Circulation 2009;120:21-7

67. Gelsomino S, Lorusso R, Romagnoli S, Bevilacqua S, De Cicco G, Billè G, Stefàno P, Gensini GF. Treatment of refractory bleeding after cardiac operations with low-dose recombinant activated factor VII (NovoSeven): a propensity score analysis. Eur J Cardiothorac Surg 2008;33:64-71

68. Mariani G, Bernardi F. Factor VII deficiency. Semin Thromb Hemost 2009;35:400-6

69. Lee GC, Kicza AM, Liu KY, Nyman CB, Kaufman RM, Body SC. Does rotational thromboelastometry (ROTEM) improve prediction of bleeding after cardiac surgery? Anesth Analg 2012;115:499-506

70. Tanaka KA, Mazzeffi MA, Grube M, Ogawa S, Chen EP. Threefactor prothrombin complex concentrate and hemostasis after high-risk cardiovascular surgery. Transfusion 2013;53:920-1

71. Arnékian V, Camous J, Fattal S, Rézaiguia-Delclaux S, Nottin R, Stéphan F. Use of prothrombin complex concentrate for excessive bleeding after cardiac surgery. Interact Cardiovasc Thorac Surg 2012;15:382-9 
72. Bolliger D, Görlinger K, Tanaka KA. Pathophysiology and treatment of coagulopathy in massive hemorrhage and hemodilution. Anesthesiology 2010;113:1205-19

73. Weber CF, Görlinger K, Meininger D, Herrmann E, Bingold T, Moritz A, Cohn LH, Zacharowski K. Point-of-care testing: a prospective, randomized clinical trial of efficacy in coagulopathic cardiac surgery patients. Anesthesiology 2012;117:531-47

74. Solomon C, Hagl C, Rahe-Meyer N. Time course of haemostatic effects of fibrinogen concentrate administration in aortic surgery. Br J Anaesth 2013;110:947-56

75. Paparella D, Brister SJ, Buchanan MR. Coagulation disorders of cardiopulmonary bypass: a review. Intensive Care Med 2004;30:1873-81

76. Levy JH, Tanaka KA. Inflammatory response to cardiopulmonary bypass. Ann Thorac Surg 2003;75:S715-20

77. Bruce D, Nokes TJ. Prothrombin complex concentrate (Beriplex $\mathrm{P} / \mathrm{N}$ ) in severe bleeding: experience in a large tertiary hospital. Crit Care 2008;12:R105

78. Ortmann E, Besser MW, Sharples LD, Gerrard C, Berman M, Jenkins DP, Klein AA. An exploratory cohort study comparing prothrombin complex concentrate and fresh frozen plasma for the treatment of coagulopathy after complex cardiac surgery. Anesth Analg 2015;121:26-33

79. Whiting D, DiNardo JA. TEG and ROTEM: technology and clinical applications. Am J Hematol 2014;89:228-32

80. Ganter MT, Hofer CK. Coagulation monitoring: current techniques and clinical use of viscoelastic point-of-care coagulation devices. Anesth Analg 2008;106:1366-75

81. Hébert PC, Wells G, Blajchman MA, Marshall J, Martin C, Pagliarello G, Tweeddale M, Schweitzer I, Yetisir E. A multicenter, randomized, controlled clinical trial of transfusion requirements in critical care. Transfusion Requirements in Critical Care Investigators, Canadian Critical Care Trials Group. N Engl J Med 1999;340:409-17

82. Karkouti K, Wijeysundera DN, Yau TM, Beattie WS, Abdelnaem E, McCluskey SA, Ghannam M, Yeo E, Djaiani G, Karski J. The independent association of massive blood loss with mortality in cardiac surgery. Transfusion 2004;44:1453-62

83. Malone DL, Dunne J, Tracy JK, Putnam AT, Scalea TM, Napolitano LM. Blood transfusion, independent of shock severity, is associated with worse outcome in trauma. J Trauma 2003;54:898-905

84. Marik PE, Corwin HL. Efficacy of red blood cell transfusion in the critically ill: a systematic review of the literature. Crit Care Med 2008;36:2667-74

85. Vamvakas EC, Blajchman MA. Transfusion-related mortality: the ongoing risks of allogeneic blood transfusion and the available strategies for their prevention. Blood 2009;113:3406-17

86. Song HK, Tibayan FA, Kahl EA, Sera VA, Slater MS, Deloughery TG, Scanlan MM. Safety and efficacy of prothrombin complex concentrates for the treatment of coagulopathy after cardiac surgery. J Thorac Cardiovasc Surg 2014;147:1036-40

87. Williams JB, Phillips-Bute B, Bhattacharya SD, Shah AA, Andersen ND, Altintas B, Lima B, Smith PK, Hughes GC, Welsby IJ. Predictors of massive transfusion with thoracic aortic procedures involving deep hypothermic circulatory arrest. J Thorac Cardiovasc Surg 2011;141:1283-8

88. Girdauskas E, Kempfert J, Kuntze T, Borger MA, Enders J, Fassl J, Falk V, Mohr FW. Thromboelastometrically guided transfusion protocol during aortic surgery with circulatory arrest: a prospective, randomized trial. J Thorac Cardiovasc Surg 2010;140:1117-24.e2

89. Schick KS, Fertmann JM, Jauch KW, Hoffmann JN. Prothrombin complex concentrate in surgical patients: retrospective evaluation of vitamin $\mathrm{K}$ antagonist reversal and treatment of severe bleeding. Crit Care 2009;13:R191

90. Stuklis RG, O'Shaughnessy DF, Ohri SK. Novel approach to bleeding in patients undergoing cardiac surgery with liver dysfunction. Eur J Cardiothorac Surg 2001;19:219-20

91. Grottke O, Braunschweig T, Spronk HM, Esch S, Rieg AD, van Oerle R, ten Cate H, Fitzner C, Tolba R, Rossaint R. Increasing concentrations of prothrombin complex concentrate induce disseminated intravascular coagulation in a pig model of coagulopathy with blunt liver injury. Blood 2011;118:1943-51
92. Taylor FB Jr, Toh CH, Hoots WK, Wada H, Levi M; Scientific Subcommittee on Disseminated Intravascular Coagulation (DIC) of the International Society on Thrombosis and Haemostasis (ISTH). Towards definition, clinical and laboratory criteria, and a scoring system for disseminated intravascular coagulation. Thromb Haemost 2001;86:1327-30

93. Arshad F, Ickx B, van Beem RT, Polak W, Grüne F, Nevens F, Ilmakunnas M, Koivusalo AM, Isoniemi H, Strengers PF, Groen H, Hendriks HG, Lisman T, Pirenne J, Porte RJ. Prothrombin complex concentrate in the reduction of blood loss during orthotopic liver transplantation: PROTON-trial. BMC Surg 2013;13:22

94. Dickneite G, Pragst I. Prothrombin complex concentrate vs fresh frozen plasma for reversal of dilutional coagulopathy in a porcine trauma model. Br J Anaesth 2009;102:345-54

95. Porta CR, Nelson D, McVay D, Salgar S, Eckert M, Izenberg S, Martin MJ. The effects of tranexamic acid and prothrombin complex concentrate on the coagulopathy of trauma: an in vitro analysis of the impact of severe acidosis. J Trauma Acute Care Surg 2013;75:954-60

96. Joseph B, Amini A, Friese RS, Houdek M, Hays D, Kulvatunyou N, Wynne J, O'Keeffe T, Latifi R, Rhee P. Factor IX complex for the correction of traumatic coagulopathy. J Trauma Acute Care Surg 2012;72:828-34

97. Schöchl H, Forster L, Woidke R, Solomon C, Voelckel W. Use of rotation thromboelastometry (ROTEM) to achieve successful treatment of polytrauma with fibrinogen concentrate and prothrombin complex concentrate. Anaesthesia 2010;65:199-203

98. Schöchl H, Nienaber U, Hofer G, Voelckel W, Jambor C, Scharbert G, Kozek-Langenecker S, Solomon C. Goal-directed coagulation management of major trauma patients using thromboelastometry (ROTEM)-guided administration of fibrinogen concentrate and prothrombin complex concentrate. Crit Care 2010;14:R55

99. Schöchl H, Schlimp CJ. Trauma bleeding management: the concept of goal-directed primary care. Anesth Analg 2014;119:1064-73

100. Tanaka KA, Bolliger D, Vadlamudi R, Nimmo A. Rotational thromboelastometry (ROTEM)-based coagulation management in cardiac surgery and major trauma. J Cardiothorac Vasc Anesth 2012;26:1083-93

101. Kerebel D, Joly LM, Honnart D, Schmidt J, Galanaud D, Negrier C, Kursten F, Coriat P; Lex206 Investigator Group. A French multicenter randomised trial comparing two doseregimens of prothrombin complex concentrates in urgent anticoagulation reversal. Crit Care 2013;17:R4

102. Aledort LM. Comparative thrombotic event incidence after infusion of recombinant factor VIIa versus factor VIII inhibitor bypass activity. J Thromb Haemost 2004;2:1700-8

103. Al-Shahi Salman R. Haemostatic drug therapies for acute spontaneous intracerebral haemorrhage. Cochrane Database Syst Rev 2009;4:CD005951

104. Mayer SA, Brun NC, Begtrup K, Broderick J, Davis S, Diringer MN, Skolnick BE, Steiner T; FAST Trial Investigators. Efficacy and safety of recombinant activated factor VII for acute intracerebral hemorrhage. N Engl J Med 2008;358:2127-37

105. O'Connell KA, Wood JJ, Wise RP, Lozier JN, Braun MM. Thromboembolic adverse events after use of recombinant human coagulation factor VIIa. JAMA 2006;295:293-8

106. Diringer MN, Skolnick BE, Mayer SA, Steiner T, Davis SM, Brun NC, Broderick JP. Thromboembolic events with recombinant activated factor VII in spontaneous intracerebral hemorrhage: results from the Factor Seven for Acute Hemorrhagic Stroke (FAST) trial. Stroke 2010;41:48-53

107. Preston FE, Laidlaw ST, Sampson B, Kitchen S. Rapid reversal of oral anticoagulation with warfarin by a prothrombin complex concentrate (Beriplex): efficacy and safety in 42 patients. Br J Haematol 2002;116:619-24

108. Goldhammer JE, Bakowitz MJ, Milas BL, Patel PA. Intracardiac thrombosis after emergent prothrombin complex concentrate administration for warfarin reversal. Anesthesiology 2015;123:458

109. Voils SA, Baird B. Systematic review: 3-factor versus 4-factor prothrombin complex concentrate for warfarin reversal: does it matter? Thromb Res 2012;130:833-40 
110. Babilonia K, Trujillo T. The role of prothrombin complex concentrates in reversal of target specific anticoagulants. Thromb J 2014;12:8

111. Levy JH, Spyropoulos AC, Samama CM, Douketis J. Direct oral anticoagulants: new drugs and new concepts. JACC Cardiovasc Interv 2014;7:1333-51

112. Levi M, Moore KT, Castillejos CF, Kubitza D, Berkowitz SD, Goldhaber SZ, Raghoebar M, Patel MR, Weitz JI, Levy JH. Comparison of three-factor and four-factor prothrombin complex concentrates regarding reversal of the anticoagulant effects of rivaroxaban in healthy volunteers. J Thromb Haemost 2014;12:1428-36

113. Eerenberg ES, Kamphuisen PW, Sijpkens MK, Meijers JC, Buller HR, Levi M. Reversal of rivaroxaban and dabigatran by prothrombin complex concentrate: a randomized, placebo-controlled, crossover study in healthy subjects. Circulation 2011;124:1573-9

114. Solbeck S, Meyer MA, Johansson PI, Meyer AS, Cotton BA, Stensballe J, Schött U, Ostrowski SR. Monitoring of dabigatran anticoagulation and its reversal in vitro by thrombelastography. Int J Cardiol 2014;176:794-9

115. Schulman S, Ritchie B, Goy JK, Nahirniak S, Almutawa M, Ghanny S. Activated prothrombin complex concentrate for dabigatran-associated bleeding. Br J Haematol 2014;164:308-10

116. Grottke O, van Ryn J, Spronk HM, Rossaint R. Prothrombin complex concentrates and a specific antidote to dabigatran are effective ex-vivo in reversing the effects of dabigatran in an anticoagulation/liver trauma experimental model. Crit Care 2014;18:R27
117. Glund S, Moschetti V, Norris S, Stangier J, Schmohl M, van Ryn J, Lang B, Ramael S, Reilly P. A randomised study in healthy volunteers to investigate the safety, tolerability and pharmacokinetics of idarucizumab, a specific antidote to dabigatran. Thromb Haemost 2015;113:943-51

118. Siegal DM, Curnutte JT, Connolly SJ, Lu G, Conley PB, Wiens BL, Mathur VS, Castillo J, Bronson MD, Leeds JM, Mar FA, Gold A, Crowther MA. Andexanet Alfa for the reversal of factor Xa inhibitor activity. N Engl J Med 2015;373:2413-24

119. Ghadimi K, Dombrowski KE, Levy JH, Welsby IJ. Andexanet Alfa for the reversal of factor Xa inhibitor related anticoagulation. Expert Rev Hematol 2016;9:115-22

120. Dolgin E. Antidotes progress for new oral clotbusters. Nat Biotechnol 2015;33:117-8

121. Enriquez A, Lip GY, Baranchuk A. Anticoagulation reversal in the era of the non-vitamin $\mathrm{K}$ oral anticoagulants. Europace 2015 [ePub ahead of print]

122. Schiele F, van Ryn J, Canada K, Newsome C, Sepulveda E, Park J, Nar H, Litzenburger T. A specific antidote for dabigatran: functional and structural characterization. Blood 2013;121:3554-62

123. Pollack CV Jr, Reilly PA, Eikelboom J, Glund S, Verhamme P, Bernstein RA, Dubiel R, Huisman MV, Hylek EM, Kamphuisen PW, Kreuzer J, Levy JH, Sellke FW, Stangier J, Steiner T, Wang B, Kam CW, Weitz JI. Idarucizumab for dabigatran reversal. N Engl J Med 2015;373:511-20 